TI 2016-017/I

Tinbergen Institute Discussion Paper

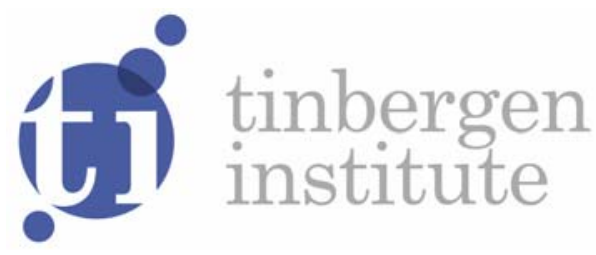

\title{
How does the Gender Difference in Willingness to Compete evolve with Experience?
}

Thomas Buser

Faculty of Economics and Business, University of Amsterdam, and Tinbergen Institute, the Netherlands. 
Tinbergen Institute is the graduate school and research institute in economics of Erasmus University Rotterdam, the University of Amsterdam and VU University Amsterdam.

More TI discussion papers can be downloaded at http://www.tinbergen.nl

Tinbergen Institute has two locations:

Tinbergen Institute Amsterdam

Gustav Mahlerplein 117

1082 MS Amsterdam

The Netherlands

Tel.: +31(0)20525 1600

Tinbergen Institute Rotterdam

Burg. Oudlaan 50

3062 PA Rotterdam

The Netherlands

Tel.: +31(0)10 4088900

Fax: +31(0)10 4089031 


\title{
How does the gender difference in willingness to compete evolve with experience?*
}

\author{
Thomas Buser ${ }^{\dagger}$
}

March 14, 2016

\begin{abstract}
I study how gender differences in willingness to compete evolve over time in response to experience. Participants in a lab experiment perform the same real-effort task over several rounds. In each round, they have to choose between piece-rate remuneration and a winner-takes-all competition. At the end of each round, those who compete get feedback on the competition outcome. The main result is that women are much more likely than men to stop competing after a loss, which leads to the appearance of a significant gender gap in competitiveness even among those who are initially willing to compete. This gender effect is also present for high performers. In an additional experiment, I show that giving feedback to non-competers might further increase the gender gap in willingness to compete as men who initially choose not to compete react more strongly to positive feedback compared to women. JEL: C91, D03, J01, J16
\end{abstract}

Keywords: competitiveness, gender, feedback, career decisions, laboratory experiment

${ }^{*}$ I would like to thank seminar and workshop participants in Amsterdam, San Francisco, São Paulo, Vienna, and Zürich for useful comments. I gratefully acknowledge financial support from the Netherlands Organisation for Scientific Research (NWO) through a personal Veni grant and would like to thank CREED for letting me use their lab.

${ }^{\dagger}$ University of Amsterdam and Tinbergen Institute. t.buser@uva.nl. School of Economics, Roetersstraat 11, 1018WB Amsterdam, The Netherlands. 


\section{Introduction}

Competition is a fact of professional life. People who want to advance in their careers are regularly confronted with situations that are in essence winner-takes-all competitions, including admission procedures to high-ranked universities, job applications, promotion tournaments, and competition between entrepreneurs. Whether an individual actively seeks out such situations or tries to avoid them will partially determine what kind of career they end up in and how far they advance up the hierarchy. Starting with Niederle and Vesterlund (2007), a large literature in experimental economics shows that women are less willing than men to enter competitions. This gender difference has attracted a lot of attention as a potential explanation for gender differences in career choices and labour market outcomes (Bertrand, 2011).

In most experimental studies, the decision to compete or not is one-shot. But in a career context, these decisions are made in a dynamic setting. To make it to the top, one has to be willing to compete repeatedly and be willing to keep competing after a setback. To empirically investigate how gender differences in willingness to compete evolve over time, I conduct an incentivised lab experiment in which participants perform the same task over a number of rounds. In each round, they decide whether they want to receive a piece-rate payment or whether they want to enter a winner-takes-all competition against a randomly selected opponent. Participants who enter the competition and outperform their opponent receive twice the piece rate, those who enter the competition and lose receive no payment in that round. After each round, participants who chose to compete learn whether they won or lost against their opponent. In an additional experiment, participants receive feedback on whether they outperformed their opponent regardless of whether they choose to compete.

The seminal study on gender differences in willingness to compete is Niederle and Vesterlund (2007). In their design, participants in a lab experiment choose between a piece-rate payment and a winner-takes-all competition against three randomly chosen opponents. Although there is no gender difference in performance, they find that twice as many men than women choose the competition. While many men are overconfident and enter the competition with low chances of winning, many high-performing women hurt their expected earnings by not competing. This result has been replicated nu-

merous times (see Croson and Gneezy, 2009, and Niederle and Vesterlund, 2011, for surveys).

A growing literature confirms the external relevance of competition decisions made in 
the lab for predicting career choices. Buser, Niederle, and Oosterbeek (2014) show that competing in an experiment predicts the study choices of Dutch high-school students and explains a significant portion of the gender gap in picking STEM majors. Zhang (2012) shows that it predicts the choice of entering a highly competitive university entrance exam in China. Reuben, Sapienza, and Zingales (2015) show that it predicts the starting salary and industry choice of graduating MBA students; Reuben, Wiswall, and Zafar (2015) show that it predicts future salary expectations of undergraduate students; and Buser, Plug, and Geijtenbeek (2015) show that it correlates with monthly earnings in a diverse sample of the Dutch population. Berge et al. (2015) show that it predicts the investment choices of Tanzanian entrepreneurs. Flory, Leibbrandt, and List (2015) run a field experiment recruiting people for real jobs and find that women are less likely to apply if compensation depends on relative performance.

An important open question is how the gender gap in competitiveness evolves over time in response to experience. If the gap is mainly due to wrong beliefs, it should shrink in response to experience if people rationally update their beliefs. ${ }^{1}$ However, a number of experimental papers suggest that men and women may react differently to winning and losing in competitions in ways which may actually enhance the gender gap. In Buser (2016), participants compete in a task and are then informed of their score and whether they won or lost. Relative to winners, male losers subsequently pick a higher individual performance target in the same task whereas female losers perform worse. Gill and Prowse (2014) similarly find that women are more prone than men to reducing their performance after losing a competition. ${ }^{2}$ Möbius et al. (2011) find that men update their beliefs about their own abilities more strongly in response to both positive and negative feedback which could perpetuate initial gender differences in confidence.

My results show that it is far from clear that the difference in willingness to compete between equally performing men and women will disappear with experience. The overall gender gap - men are initially 14 percentage points more likely to compete conditional on performance - diminishes somewhat over the rounds. But a large and persistent

\footnotetext{
${ }^{1}$ Starting with Niederle and Vesterlund (2007), many experiments show that women are less confident than men. Wozniak, Harbaugh, and Mayr (2014) show that when people receive detailed relative performance feedback prior to choosing the payment scheme, the gender gap in competitiveness is substantially reduced.

${ }^{2}$ A separate literature started by Gneezy, Niederle, and Rustichini (2003) shows that men's performance tends to increase more strongly in response to competitive pressure than women's but a large number of studies show that this is not the case for the task used in my experimental design (Niederle and Vesterlund, 2011).
} 
gender gap appears over time even for those individuals who are initially willing to compete. Women who chose competition in round 1 are 21 percentage points less likely to compete again in round 2 compared to men who chose competition in round 1. This difference is still 15 percentage points in the last round. Even more striking is the fact that these differences are larger for high performers who, in expectation, will gain financially from competing. In the final round, high-performing women who were initially willing to compete are 24 percentage points less likely to compete than comparable men.

The root of this emerging gender gap is a large gender difference in the reaction to losing the competition in round 1 . Women who compete and lose are much more likely to stop competing than men who compete and lose. This also applies to high performers, who have a larger than 50 percent chance of winning the competition. In an additional experiment, where those who choose not to compete get equivalent feedback to those who compete, I replicate the main results: a large gender gap appears even for those who initially compete and this is due to a gender difference in the reaction to losing the competition. Additionally, I find that with feedback, a gender difference in willingness to compete also appears for those who initially do not compete. The reason is a gender difference in the reaction to positive feedback. Men who initially do not compete are more likely than women to start and keep competing over the following rounds. I explore the role of confidence and belief updating and discuss what my results imply for our understanding of gender differences in career choices and labour market outcomes, in particular the low number of women of women in top positions in science and business.

The rest of the paper is structured as follows. Section 2 explains the experimental design. Section 3 presents the results. Section 4 discusses and concludes.

\section{Experimental design}

The experimental design is based on Niederle and Vesterlund (2007). Participants earn money for their performance in a real effort task which consists in adding up sets of five two-digit numbers. Participants have three minutes per round to solve as many problems as they can. Wrong answers are not penalised. Before the start of the incentivised part of the experiment, there is a three-minute practice round after which the participants learn their score but receive no relative feedback. 
After the practice, the experiment consists of six rounds. In each round, participants are paired with a new randomly chosen, anonymous opponent and have to choose how they would like to be paid for their performance in the adding-up-numbers task. They can choose between piece-rate and competitive remuneration. If they choose the piece rate, they receive one point per correct answer regardless of the performance of their opponent. If they choose competition, they receive two points per correct answer if they score higher than their opponent and nothing if they do not. ${ }^{3}$ Opponents are randomly chosen amongst all other participants regardless of their choice. One point is worth 25 Euro cents and all rounds were paid.

After each round, participants who choose competition receive feedback on their absolute and relative performance. That is, they learn their score and whether they won or lost against their opponent (the feedback reads "You scored X correct answers. You scored higher (lower) than your opponent. You won (lost) against your opponent.").

Before the start of each round, I elicit an incentivised measure of participants' beliefs about their own performance. Participants are asked to predict their rank compared to all other participants in their session in the upcoming round. If their guess is within plus-minus one of the true rank, they receive a bonus of four points. At the end of the last round, before they see a screen which summarises their earnings, participants fill in a short questionnaire asking for their gender and age and eliciting their perception about their own willingness to take risk and their own competitiveness.

To elicit risk attitudes, I asked "How do you see yourself: Are you generally a person who is fully prepared to take risks or do you try to avoid taking risks?" (Dohmen et al., 2011). The answer is on a scale from 0 ("unwilling to take risks") to 10 ("fully prepared to take risk"). To elicit competitive attitudes, I ask an analogous question, "How competitive do you consider yourself to be? Please choose a value on the scale below, where the value 0 means 'not competitive at all' and the value 10 means 'very competitive"".

To summarise, in each of the six rounds the timeline is as follows. Participants

1. Predict their rank in the upcoming round compared to all other participants present in the lab,

2. Choose between competitive and piece-rate payment schemes,

3. Perform in the task,

4. Learn their score and, if they chose competition, whether or not they beat their

\footnotetext{
${ }^{3}$ In case of a tie, winning or losing was randomly determined.
} 
opponent

A total of 188 individuals participated in 7 sessions with 21 to 31 participants each. All sessions were roughly gender-balanced. The sessions were run in November 2015 at the CREED lab at the University of Amsterdam using z-Tree. Participants earned 21.2 Euros on average including a 7-Euro show-up fee.

\section{Results}

\subsection{Evolution of the gender gap in willingness to compete over time}

In this section, I will analyse how the willingness to compete of men and women evolves over the six rounds of the experiment. Table 1 shows descriptive statistics of average choices over all rounds and questionnaire measures by gender. Over all rounds, men scored slightly higher compared to women, although this difference is not statistically significant. Men are significantly more confident and more likely to choose competition over piece rate. ${ }^{4}$ Men also earn more than women over all rounds although this difference is not statistically significant. Men judge themselves to be significantly more risk-taking and competitive.

Figure 1 shows the proportion of participants who choose the competition in each round separately by gender. Men are more likely than women to choose competition over piece rate in all rounds of the experiment. In round 1, men are 14 percentage points more likely to compete than women $(\mathrm{p}=0.06$, chi-squared test). This gender gap increases slightly to 15 percentage points in round $2(\mathrm{p}=0.04)$, shrinks to 10 percentage points in round 3 and increases again to 14 percentage points in round $4(\mathrm{p}=0.06)$. In the last round, men are still 9 percentage points more likely to compete $(\mathrm{p}=0.19)$.

Figure 2 shows the likelihood of competing for men and women who choose competition in round 1. Strikingly, even for these people, who are initially willing to compete, a large gender difference appears in round 2. 87 percent of men who compete in round 1 still compete in round 2 whereas for women this number is only 65 percent $(\mathrm{p}=0.02)$. By round 4, 77 percent of men and 55 percent of women who initially choose competi-

\footnotetext{
${ }^{4}$ Confidence corresponds to the probability of winning as predicted by the participants themselves and is based on the rank predictions of the participants. It is calculated as (predicted \# of participants with lower score)/(\# of participants-1).
} 
Table 1: Descriptive statistics

\begin{tabular}{lccccc}
\hline & & $(1)$ & $(2)$ & $(3)$ & $(4)$ \\
& Scale & All & Male & Female & P-val \\
\hline Score & $0-19$ & 7.30 & 7.54 & 7.07 & 0.243 \\
& & $(2.99)$ & $(3.20)$ & $(2.76)$ & \\
Confidence & $0-1$ & 0.59 & 0.63 & 0.55 & 0.012 \\
& & $(0.25)$ & $(0.24)$ & $(0.26)$ & \\
Choosing competition & binary & 0.47 & 0.53 & 0.41 & 0.046 \\
& & $(0.50)$ & $(0.50)$ & $(0.49)$ & \\
Earnings & $0-10$ & 2.37 & 2.56 & 2.18 & 0.109 \\
& & $(2.02)$ & $(2.21)$ & $(1.80)$ & \\
\hline Risk taking & $0-10$ & 5.5 & 6.0 & 5.0 & 0.006 \\
& & $(2.45)$ & $(2.33)$ & $(2.47)$ & \\
Competitiveness & $0-10$ & 6.7 & 7.1 & 6.3 & 0.034 \\
& & $(2.39)$ & $(2.20)$ & $(2.51)$ & \\
\hline $\mathrm{N}$ & & 188 & 93 & 85 &
\end{tabular}

Note: The table shows averages over all six rounds. Confidence is the probability of winning as predicted by the participants themselves at the start of the round. Earnings are per-round earnings in Euros. Risk-taking and competitiveness are self-rated questionnaire measures. Column 4 shows p-values from t-tests of the gender difference.

Figure 1: Willingness to compete by gender and round

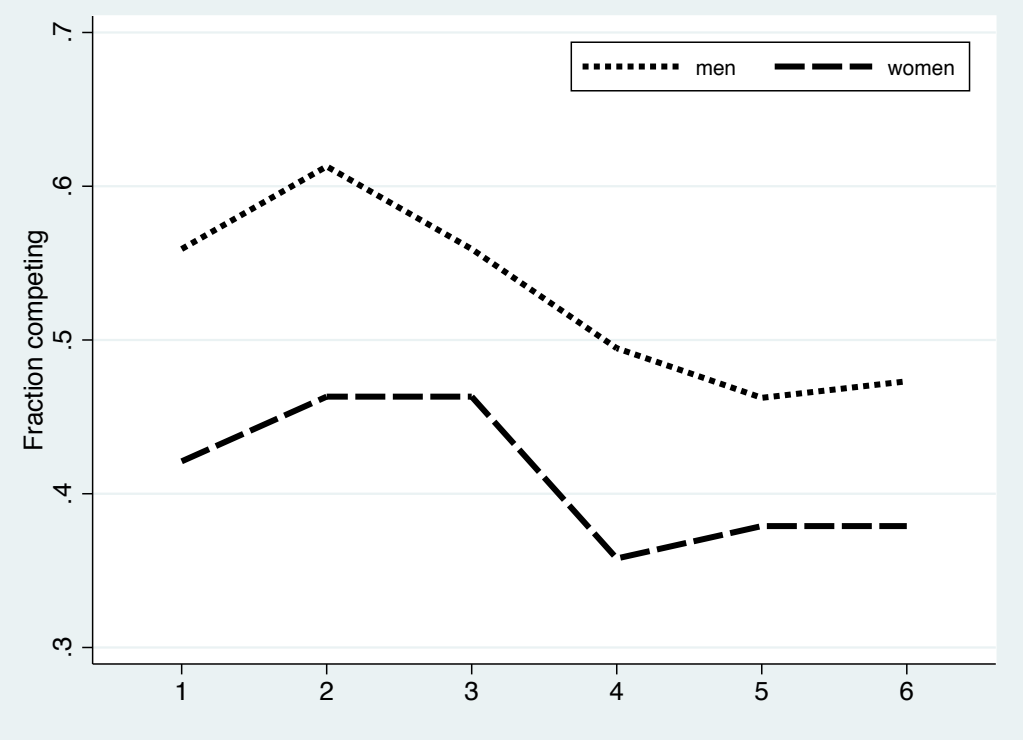


Figure 2: Willingness to compete by gender and round (participants who choose competition in round 1)

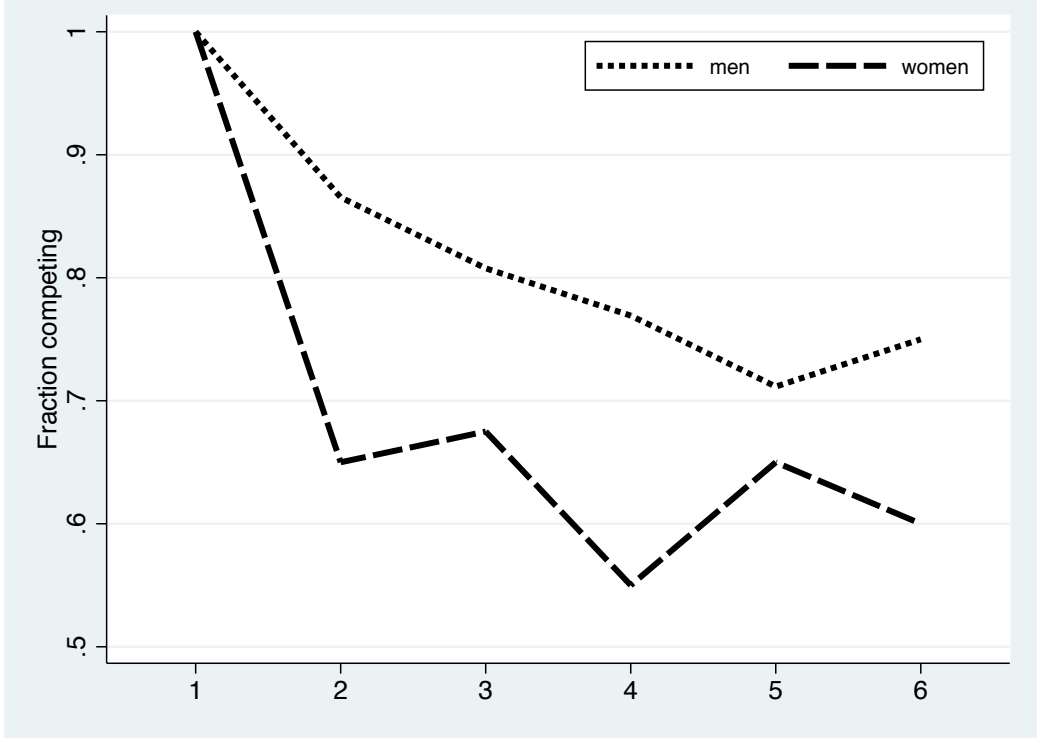

tion still compete $(\mathrm{p}=0.03)$. In the last round, men in this group are still 15 percentage points more likely to compete $(\mathrm{p}=0.13)$.

Figure 3 shows the likelihood of competing for men and women who choose the piece rate in round 1 . Among this group, a similar proportion of men and women start to compete in round 2 (29 percent and 33 percent, $\mathrm{p}=0.72$ ). Over the following rounds, women who initially chose the piece-rate are slightly but not significantly more likely to compete than men who initially chose the piece-rate (the difference ranges from 3 to 10 percentage points).

Panel A of Table 2 repeats the analysis in Figures 1 to 3 using OLS regressions controlling for absolute performance and chance of winning (rank) in round $1 .{ }^{5}$ Columns 1 to 6 show regressions of the remuneration choice in each of rounds 1 to 6 on gender. The regression results show that the gender difference in choosing the competition looks very similar when controlling for performance, meaning that gender differences in performance cannot explain the gender difference in willingness to compete. For the sample as a whole, the gender difference is 14 percentage points initially and fluctuates between 7 and 15 percentage points over rounds 2 to 6 .

Panel A of Table 2 also shows separate regressions for the gender gap in rounds 2

\footnotetext{
${ }^{5}$ Chance of winning and is calculated as (\# of participants with lower score)/(\# of participants-1) and therefore corresponds to rank normalised by the number of subjects in a session.
} 
Table 2: Gender gap in competition entry in each round

\begin{tabular}{|c|c|c|c|c|c|c|c|c|}
\hline \multicolumn{9}{|c|}{ Panel A: all observations } \\
\hline & & (1) & $(2)$ & (3) & (4) & (5) & (6) & (7) \\
\hline & & Round 1 & Round 2 & Round 3 & Round 4 & Round 5 & Round 6 & Pooled (2-6) \\
\hline \multirow{3}{*}{ All } & Female & $-0.135^{*}$ & $-0.146^{* *}$ & -0.091 & $-0.125^{*}$ & -0.068 & -0.085 & $-0.103^{* *}$ \\
\hline & & $(0.071)$ & $(0.066)$ & $(0.067)$ & $(0.068)$ & $(0.063)$ & $(0.064)$ & $(0.051)$ \\
\hline & $\mathrm{N}$ & 188 & 188 & 188 & 188 & 188 & 188 & 940 \\
\hline \multirow{3}{*}{$\begin{array}{l}\text { Comp. in } \\
\text { round } 1\end{array}$} & Female & & $-0.214^{* * *}$ & -0.117 & $-0.215^{* *}$ & -0.043 & $-0.152^{*}$ & $-0.148^{* *}$ \\
\hline & & & $(0.065)$ & $(0.081)$ & $(0.095)$ & $(0.086)$ & $(0.085)$ & $(0.059)$ \\
\hline & $\mathrm{N}$ & & 92 & 92 & 92 & 92 & 92 & 460 \\
\hline \multirow{6}{*}{$\begin{array}{l}\mathrm{PR} \text { in } \\
\text { round } 1\end{array}$} & Female & & -0.023 & 0.014 & 0.041 & -0.021 & 0.030 & 0.008 \\
\hline & & & $(0.100)$ & $(0.093)$ & $(0.081)$ & $(0.079)$ & $(0.083)$ & $(0.058)$ \\
\hline & $\mathrm{N}$ & & 96 & 96 & 96 & 96 & 96 & 480 \\
\hline & R1 score & $\sqrt{ }$ & $\sqrt{ }$ & $\sqrt{ }$ & $\sqrt{ }$ & $\sqrt{ }$ & $\sqrt{ }$ & $\sqrt{ }$ \\
\hline & R1 rank & $\sqrt{ }$ & $\sqrt{ }$ & $\sqrt{ }$ & $\sqrt{ }$ & $\sqrt{ }$ & $\sqrt{ }$ & $\sqrt{ }$ \\
\hline & R1 outcome & & $(\sqrt{ })$ & $(\sqrt{ })$ & $(\sqrt{ })$ & $(\sqrt{ })$ & $(\sqrt{ })$ & $(\sqrt{ })$ \\
\hline
\end{tabular}

\begin{tabular}{|c|c|c|c|c|c|c|c|c|}
\hline \multicolumn{9}{|c|}{ Panel B: chance of winning $>0.5$} \\
\hline & & $(1)$ & $(2)$ & $(3)$ & $(4)$ & $(5)$ & $(6)$ & $(7)$ \\
\hline & & Round 1 & Round 2 & Round 3 & Round 4 & Round 5 & Round 6 & Pooled (2-6) \\
\hline \multirow{3}{*}{ All } & Female & -0.112 & $-0.169^{*}$ & -0.073 & $-0.161^{*}$ & -0.087 & -0.139 & $-0.125^{*}$ \\
\hline & & $(0.105)$ & $(0.092)$ & $(0.097)$ & $(0.090)$ & $(0.092)$ & $(0.092)$ & $(0.073)$ \\
\hline & $\mathrm{N}$ & 92 & 92 & 92 & 92 & 92 & 92 & 460 \\
\hline \multirow{3}{*}{$\begin{array}{l}\text { Comp. in } \\
\text { round } 1\end{array}$} & Female & & $-0.235^{* * *}$ & $-0.148^{*}$ & $-0.283^{* *}$ & -0.117 & $-0.241^{* *}$ & $-0.205^{* * *}$ \\
\hline & & & $(0.078)$ & $(0.087)$ & $(0.112)$ & $(0.097)$ & $(0.095)$ & $(0.066)$ \\
\hline & $\mathrm{N}$ & & 55 & 55 & 55 & 55 & 55 & 275 \\
\hline \multirow{6}{*}{$\begin{array}{l}\mathrm{PR} \text { in } \\
\text { round } 1\end{array}$} & Female & & 0.116 & 0.181 & 0.082 & 0.024 & 0.135 & 0.108 \\
\hline & & & $(0.144)$ & $(0.192)$ & $(0.144)$ & $(0.152)$ & $(0.146)$ & $(0.107)$ \\
\hline & $\mathrm{N}$ & & 37 & 37 & 37 & 37 & 37 & 185 \\
\hline & R1 score & $\sqrt{ }$ & $\sqrt{ }$ & $\sqrt{ }$ & $\sqrt{ }$ & $\sqrt{ }$ & $\sqrt{ }$ & $\sqrt{ }$ \\
\hline & R1 rank & $\sqrt{ }$ & $\sqrt{ }$ & $\sqrt{ }$ & $\sqrt{ }$ & $\sqrt{ }$ & $\sqrt{ }$ & $\sqrt{ }$ \\
\hline & R1 outcome & & $(\sqrt{ })$ & $(\sqrt{ })$ & $(\sqrt{ })$ & $(\sqrt{ })$ & $(\sqrt{ })$ & $(\sqrt{ })$ \\
\hline
\end{tabular}

Note: The table shows coefficients from OLS regressions of a gender dummy on a binary indicator for choosing the competition. Each line is a separate regression. Columns 1 to 6 use data from rounds 1 to 6 respectively. Column 7 shows coefficients from regressions with pooled data from rounds 2 to 6 . R1 score, $\mathrm{R} 1$ rank and $\mathrm{R} 1$ outcome means score, normalised withinsession rank and the competition outcome in round 1. All regressions control for session fixed effects. Robust standard errors in parentheses. Standard errors from the pooled regressions in column 7 are clustered at the individual level. 
Figure 3: Willingness to compete by gender and round (participants who choose piece rate in round 1 )

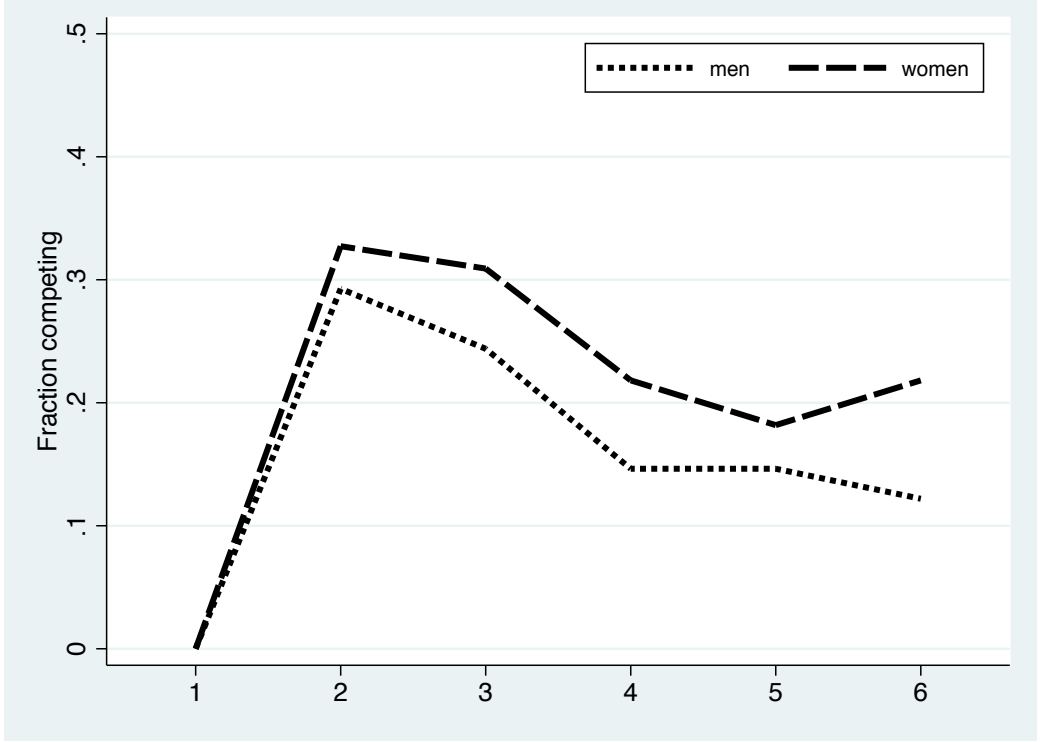

to 6 for those who choose competition in round 1 and those who choose piece rate in round 1. The regressions confirm that a significant gender gap appears from round 2 onwards for those who initially compete. In round 2, a woman who chooses competition in round 1 is 21 percentage points less likely to compete than a man with the same round 1 choice, same performance, same within-session rank, and same competition outcome in round 1. The gender difference fluctuates between 12 and 22 percentage points over the following rounds and is still 15 percentage points in the last round. The pooled regression in column 7 shows that the average woman who chooses to compete in round 1 is 15 percentage points less likely to compete in each of the following 5 rounds compared to the average man. For those who initially choose the piece rate, controlling for absolute and relative performance the gender difference is close to zero in all subsequent rounds.

To judge whether the persistent gender gap in willingness to compete is financially bad for women, it is important to know whether it is due to high performers (in which case high-performing women would lose out by shying away from competitions they are likely to win) or due to low performers (in which case men would be hurting themselves by entering competitions they are unlikely to win). Panel B of Table 2 shows gender regressions for the subsample of participants whose likelihood to compete is higher than 50 percent and who therefore financially gain from entering the competition in 
expectation. ${ }^{6}$ The regression results show that the gender gap for high performers is similar to the gap for the sample as a whole, although the coefficients are less precisely estimated due to the lower sample size.

A striking pattern again emerges for those who are initially willing to compete. The gender gap in choosing competition, which emerges for this group from round 2 onwards, is even larger and more significant for high performers. Amongst men and women who are initially willing to compete and who are likely to win, women are 24 percentage points less likely to compete again in round 2. And this difference does not attenuate over time. In the final round, high-performing women are still 24 percentage points less likely to compete than high-performing men. Among those participants who initially choose the piece rate but who have a high chance of winning, women are actually more likely to choose competition from round 2 onwards. But this difference is imprecisely estimated due to the lower number of observations in this group.

\subsection{Gender difference in the effect of losing on subsequent will- ingness to compete}

I will now investigate whether the large proportion of women who drop out of competition and the resulting emergence of a gender gap in round 2 is due to a gender difference in the reaction to competition outcomes. In particular, I will answer the question whether women who initially choose to compete are more likely than their male counterparts to stop competing following a loss.

Figure 4 shows how often on average participants choose to compete in rounds 2 to 6 , split by their gender, their choice of remuneration scheme in round 1, and, for those who initially compete, whether they won or lost in round 1 . The two left-most panels show competition rates for those participants who choose to compete in round 1. Participants of both genders who win the competition mostly keep competing over the following three rounds (4.6 out of 5 times for men and 4.2 out of 5 times times for women; $\mathrm{p}=0.17$, t-test). However, the reaction to losing in round 1 differs strongly between men and women. Men who initially compete and lose compete a further 2.6 out of 5 times whereas for women this is only 1.1 times $(\mathrm{p}=0.04)$. The two right-most panels show competition rates for those participants who choose the piece rate in round 1. Both men and women in this group only rarely choose to compete over the following

\footnotetext{
${ }^{6}$ Chance of winning is calculated within session based on first-round performance as (\# of participants with lower score)/(\# of participants-1).
} 
Figure 4: Average number of times competition is chosen in rounds 2 to 6 by gender, initial choice and competition outcome in round 1
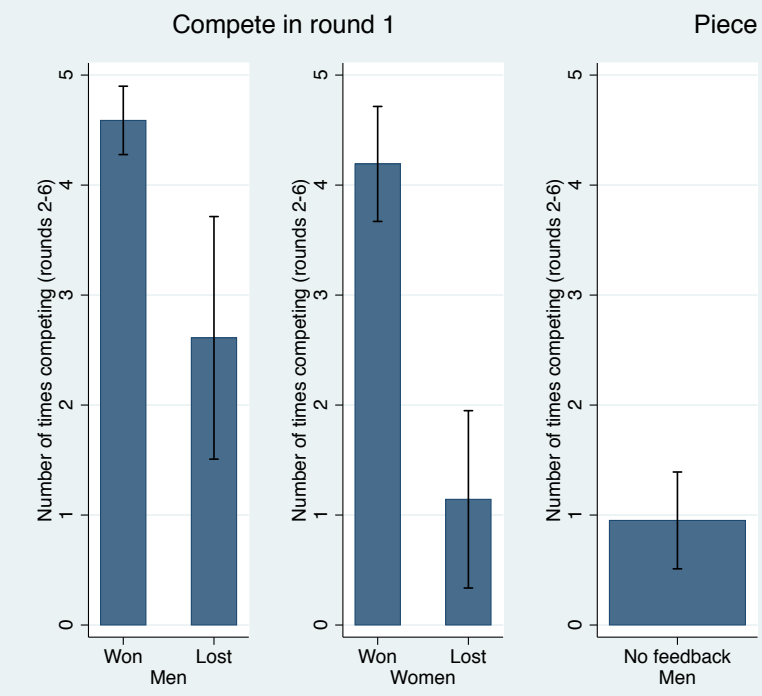

Piece rate in round 1

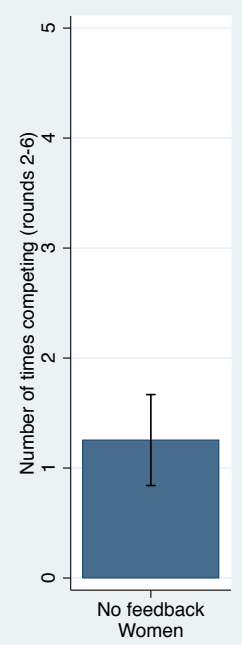

Note: The bars show the average number of times that participants chose to compete over rounds 2 to 6. "Lost" denotes participants who lost in round 1 and "won" denotes participants who won in round 1.

five rounds (1.0 and 1.3 times respectively, $\mathrm{p}=0.32$ ).

In Table 3, I use OLS regressions to confirm the robustness of the gender difference in the reaction to losing. Here, I regress a binary indicator for choosing to compete in rounds 2 to 6 on a gender dummy, a binary indicator for having lost in round 1, and the interaction of the two. The regressions control for score fixed effects and within-session rank (likelihood of winning) in round 1. It is important to note that conditional on score fixed effects, winning or losing in round 1 only depends on the score of the randomly allocated opponent and can consequently be interpreted as a random treatment. The regressions therefore give us causal estimates of the effect of losing relative to winning in round 1 on the likelihood of competing in the five subsequent rounds.

The regression in column 1 of Table 3 uses the sample of all participants who choose to compete in round 1 . The results show that the gender difference in the reaction to losing is robust to controlling for absolute and relative performance. Whereas male losers are 24 percentage points less likely to enter competition in rounds 2 to 6 compared to winners, this effect is more than twice as large for women at 59 percentage points. Column 2 restricts the sample to participants who scored from 4 to 10 points in round 2 , which is the range of scores for which there is overlap between winners and losers 
Table 3: Competition entry in rounds 2 to 6

\begin{tabular}{|c|c|c|c|c|}
\hline & (1) & (2) & (3) & (4) \\
\hline & \multicolumn{2}{|c|}{ All observations: } & \multicolumn{2}{|c|}{ Chance of winning $>0.5$ : } \\
\hline & All scores & $4 \leq$ Score $\leq 10$ & All scores & $4 \leq$ Score $\leq 10$ \\
\hline \multirow[t]{2}{*}{ Female } & -0.065 & -0.047 & $-0.132^{* *}$ & -0.105 \\
\hline & $(0.056)$ & $(0.065)$ & $(0.053)$ & $(0.070)$ \\
\hline \multirow[t]{2}{*}{ Round 1 loser } & $-0.240^{*}$ & -0.201 & -0.149 & -0.137 \\
\hline & $(0.126)$ & $(0.129)$ & $(0.156)$ & $(0.158)$ \\
\hline \multirow[t]{2}{*}{ Female $x$ loser } & $-0.349^{* *}$ & $-0.441^{* * *}$ & $-0.409^{* *}$ & $-0.432^{* *}$ \\
\hline & $(0.144)$ & $(0.151)$ & $(0.186)$ & $(0.192)$ \\
\hline Score fixed effects & $\sqrt{ }$ & $\sqrt{ }$ & $\sqrt{ }$ & $\sqrt{ }$ \\
\hline Round 1 rank & $\sqrt{ }$ & $\sqrt{ }$ & $\sqrt{ }$ & $\sqrt{ }$ \\
\hline Observations & 460 & 370 & 275 & 210 \\
\hline Individuals & 92 & 74 & 55 & 42 \\
\hline
\end{tabular}

Note: The table shows coefficients from OLS regressions of a gender dummy, a dummy for having lost the round 1 competition and the interaction of the two on a binary indicator for choosing the competition in rounds 2 to 6 . Each choice is a separate observation and standard errors are clustered at the individual level. The sample consists of participants who choose competition in round 1. Score and round 1 rank mean score and normalised within-session rank in round 1. Clustered standard errors in parentheses.

(that is, for each score from 4 to 10 there are both winners and losers). This sample still includes probabilities of winning from 4 to 93 percent. The estimate of the gender difference in the reaction to losing is slightly larger.

Again, it is interesting to check whether the gender difference in the reaction to losing applies also for those individuals who have a higher than 50 percent chance of winning. If this is the case, losing early on would be much more costly for high-performing women than for high-performing men. The results in column 3 of Table 3 show that while high-performing men hardly react to losing in round 1, high-performing women who lose are more than 55 percentage points less likely to choose competition again over the subsequent rounds compared to high-performing women who win. Column 4 shows that this result also holds for the subsample of high performers who scored from 4 to 10 points in round 2 .

\subsection{The role of feedback for non-competers}

Up to now, have to compete to receive feedback, a design point which mirrors a feature of many real-life career situations (one has to apply for a job to find out whether one could get it, for example). However, it is interesting to ask what would happen if 
those who choose the piece rate receive feedback which is equivalent to the feedback received by those who compete. Potentially, the gender gap could be reduced as high performers who start out choosing the piece rate or drop out of competition after a loss are encouraged by positive feedback to (re-)enter competition.

To examine the impact of feedback for non-competers, I ran another lab experiment. Participants solve addition problems over four rounds of four minutes each. In each round, they are allocated to a new randomly selected opponent and choose between competition and piece rate. The difference is that participants now learn whether they outperformed their opponent even if they choose the piece rate (for participants who choose the piece rate, the message reads "You scored X correct answers. You scored higher (did not score higher) than your opponent. You therefore would have won (lost) against your opponent." $)^{7}$

Descriptive statistics look similar to the previously described experiment. Over all rounds men performed slightly but not significantly better than women. They were also significantly more confident and significantly more likely to choose the competition. They also earned significantly more. Again, men judged themselves to be more risk-seeking and competitive, although only the second of these gender differences is statistically significant. $^{8}$

Figure 5 shows the proportion of participants who choose the competition in each round separately by gender. The gender difference in the likelihood of choosing to compete is initially only 5 percentage points $(\mathrm{p}=0.53$, chi-squared test). But this grows to around 16 percentage points in round $2(\mathrm{p}=0.03)$ and stays roughly constant in rounds 3 and $4(\mathrm{p}=0.03$ in each round). A potential reason for the small initial gender gap is that, contrary to the main experiment (and contrary to the standard design in the literature on gender differences in competitiveness), it is no longer possible to avoid relative feedback by staying away from the competition. Women have been found to be more feedback averse than men on average (Möbius et al., 2011) which might encourage choosing the piece rate if this allows to avoid relative feedback.

Figure 6 shows the likelihood of competing for men and women who choose com-

\footnotetext{
${ }^{7} \mathrm{~A}$ total of 184 individuals participated in 7 sessions with 21 to 31 participants each. All sessions were roughly gender-balanced. The sessions were run in January 2015 at the CREED lab at the University of Amsterdam using z-Tree (Fischbacher, 2007). Participants earned 20.8 Euros on average including a 7-Euro show-up fee.

${ }^{8}$ Scores: 10.7 (men) vs 9.9 points (women); $\mathrm{p}=0.14$, t-test. Confidence: 0.64 vs $0.53 ; \mathrm{p}=0.00$. Choosing competition: 0.53 vs $0.40 ; \mathrm{p}=0.03$. Earnings: 3.82 vs $3.02 ; \mathrm{p}=0.02$. Risk taking: 5.6 vs 5.1 ; $\mathrm{p}=0.28$. Competitiveness: 7.2 vs $6.4 ; \mathrm{p}=0.04$.
} 
Figure 5: Willingness to compete by gender and round (feedback experiment)

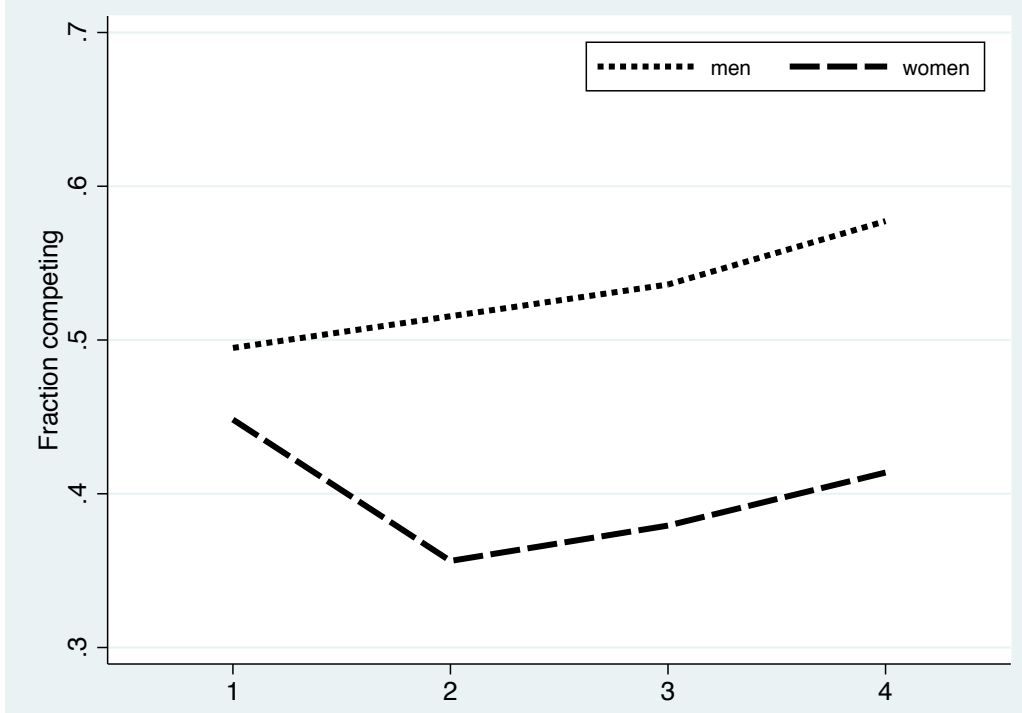

Figure 6: Willingness to compete by gender and round (participants who choose competition in round 1; feedback experiment)

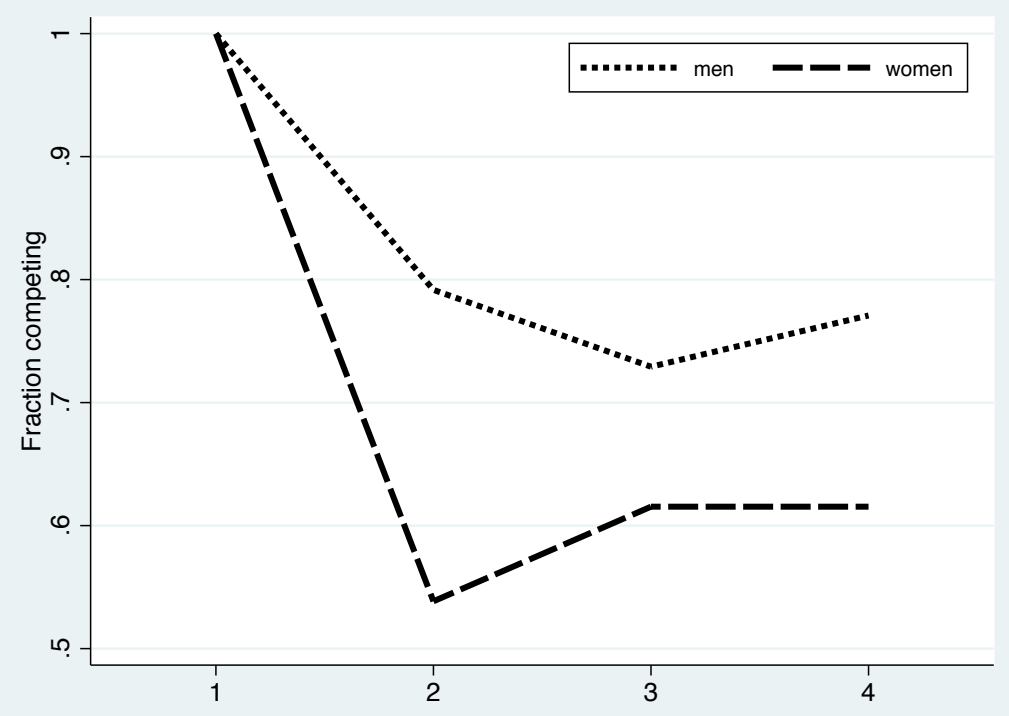


Figure 7: Willingness to compete by gender and round (participants who choose piece rate in round 1 ; feedback experiment)

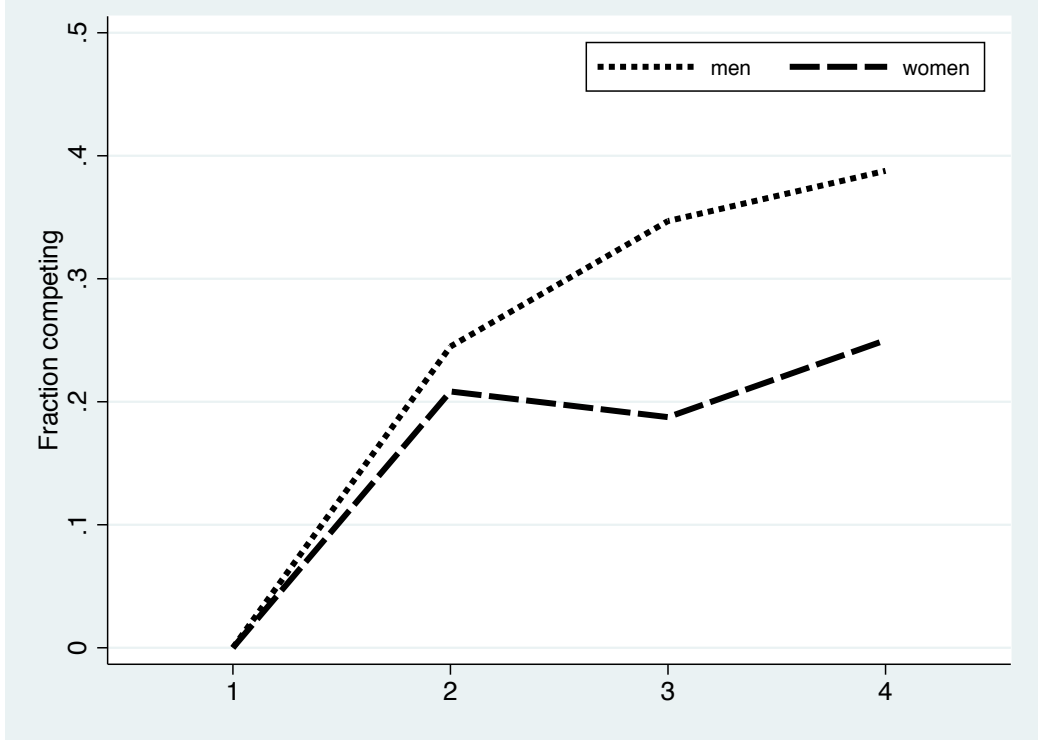

petition in round 1. The pattern looks remarkably similar to the one in Figure 2. A large and statistically significant gender difference appears in round 2. In percentage terms, 79 percent of men who compete in round 1 still compete in round 2, whereas for women this is only 54 percent $(\mathrm{p}=0.01)$. By round 4,77 percent of men and 62 percent of women who initially choose competition still compete $(\mathrm{p}=0.12)$.

Figure 7 shows the likelihood of competing for men and women who choose the piece rate in round 1 . Despite the fact that those who outperform their opponent now receive positive feedback, a smaller proportion than in the main experiment decide to enter in round 2. The pattern we observe from round 3 onwards looks very different from the one in Figure 3. First, a gender gap appears in round 3 with 35 percent of men and 19 percent of women choosing to compete $(\mathrm{p}=0.08)$. In round 4 , this is 39 percent and 25 percent $(\mathrm{p}=0.15)$. Second, whereas in the main experiment, competition entry steadily declines after its peak in round 2, it now keeps increasing in rounds 3 and 4.

The likeliest explanation for these differences is that without feedback, the "wrong" people choose to enter competition after round 1, whereas now only those who receive positive feedback choose to enter. Indeed, the mean chance of winning (in round 1) of those who choose to enter in round 2 is 61 percent compared to 48 percent in the main experiment. Furthermore in the main experiment, a mere 30 percent of those who start with choosing the piece rate but have a higher than 50 percent chance of 
winning choose competition by round 4 (32 percent by round 6 ). With feedback for non-competers, the corresponding figure is 74 percent. The biggest difference between the two experiments appears for men who initially choose the piece rate. Whereas in the the main experiment, 15 percent of these men enter competition in round 4, this is now 39 percent (for women, the corresponding numbers are 22 and 25 percent).

Table 4 repeats the analysis in Figures 5 to 7 using OLS regressions controlling for absolute and relative performance in round 1 as well as the feedback participants received at the end of round 1 . Columns 1 to 4 show regression results for rounds 1 to 4. In column 5, I repeat the analysis for round 4 while additionally controlling for the feedback that participants receive (that is, the competition outcome) in rounds 3 and 4. Column 5 therefore shows the difference in tournament entry in round 4 between men and women who have the same initial performance and rank and who received the same feedback in rounds 1 to 3 .

The regressions for the whole sample show that the gender gap in rounds 2 to 4 is statistically significant at the 10-percent level when controlling for absolute and relative performance in round 1 (columns 2 to 4). By round 4, a woman is 11 percentage points less likely to compete compared to a man with the same initial performance and rank who received the same feedback after round 1. Additionally controlling for the competition outcomes in rounds 2 and 3 in column 5 increases precision but does not the affect the estimate of the gender gap, further confirming that gender differences in performance cannot explain the emerging gender gap in willingness to compete.

Table 4 also shows separate regressions for those who choose competition and those who choose piece rate in round 1 . For those who initially choose competition, a large and significant gender gap of 25 percentage points emerges in round 2. By round 4, the average woman who started out competing is still 18 percentage points less likely to compete than the average man who started out competing. Column 5 shows that differences in differences in received feedback cannot explain this gender difference. The pooled regression in column 6 shows that the average woman who competes in round 1 is 18 percentage points less likely to compete over rounds 2 to 4 than the average man who competes in round 1 conditional on absolute and relative performance and the competition outcome in round 1.

For those who choose the piece rate in round 1, a gender gap of around 11 percentage points emerges in rounds 3 and 4 but this is only statistically significant at the tenpercent level in round 4 when additionally controlling for the received feedback in rounds 2 and 3 in column 5. 
Table 4: Gender gap in competition entry in each round (feedback experiment)

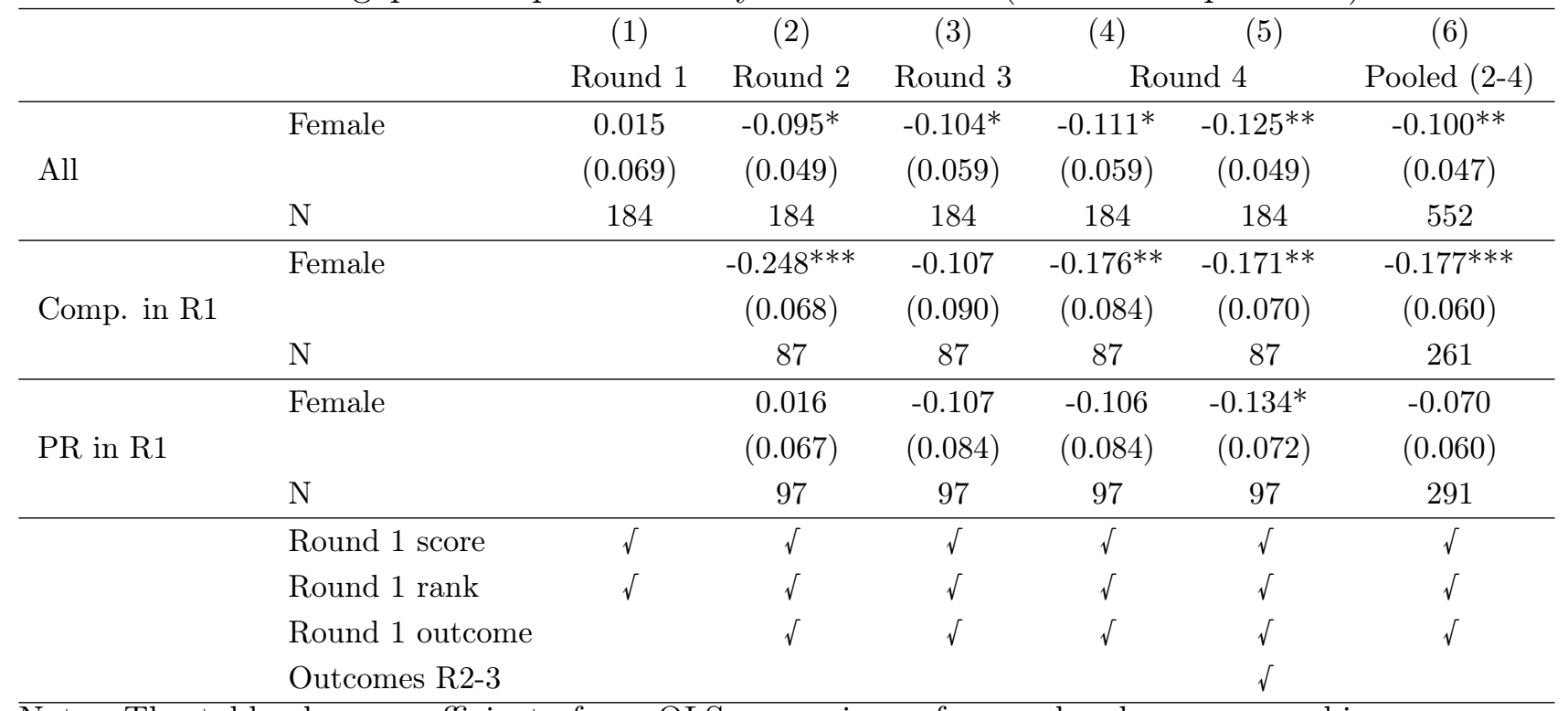

Note: The table shows coefficients from OLS regressions of a gender dummy on a binary indicator for choosing the competition. Each line is a separate regression. Columns 1 to 4 use data from rounds 1 to 4 respectively. Column 6 shows coefficients from regressions with pooled data from rounds 2 to 4 . Round 1 score, round 1 rank and round 1 outcome means score, normalised within-session rank and the competition outcome in round 1. All regressions control for session fixed effects. Robust standard errors in parentheses. Standard errors from the pooled regressions in column 6 are clustered at the individual level. 
I will now investigate whether the gender gaps that emerge over time both for those who are initially willing to compete and those who initially choose the piece rate are due to gender differences in the reaction to competition outcomes. Figure 8 replicates the analysis in Figure 4. The two left-most panels show the average number of times participants choose competition over rounds 2 to 4 for those who choose competition in round 1 separately by gender and the competition outcome in round 1 . The results from the main experiment replicate. Both men and women essentially keep competing if they win in round 1 (2.9 out of 3 times for men and 2.8 out of 3 times for women; $\mathrm{p}=0.50$, t-test). But women who lose are on average much less likely to compete over the following rounds than men who lose (1.5 out of 3 times for men and 0.6 out of 3 times for women; $\mathrm{p}=0.02)$.

Giving feedback to non-competers also allows me to test whether there is a gender difference in the reaction to positive feedback for those who are initially not willing to compete. The two right-most panels of Figure 8 show the average number of times participants choose competition over rounds 2 to 4 for those who choose piece rate in round 1 separately by gender and the feedback received at the end of round 1 . There is no gender difference for those who perform worse than their opponent in round 1: both men and women essentially keep choosing the piece rate (men compete 0.2 out of 3 times and women 0.3 out of 3 times; $\mathrm{p}=0.57$ ). But men who outperform their opponent compete more often over the following rounds than women who outperform their opponent (2.4 out of 3 times vs 1.5 out of 3 times; $\mathrm{p}=0.02$ ).

These results replicate the gender difference in the reaction to losing a competition that I found in the main experiment and indicate that there is also a gender difference in the reaction to positive feedback ("winning") for those who are initially not willing to compete. In Table 5, I regress a binary indicator for choosing to compete in rounds 2 to 4 on a gender dummy, a binary indicator for having lost (won) in round 1, and the interaction of the two, separately for those who choose competition in round 1 and those who choose piece rate. The regressions control for score fixed effects and within-session rank (likelihood of winning) in round 1. In columns 2 and 4, I restrict the sample to individuals who scored from 6 to 13 points, the scores for which there are both winners and losers. Again, it is important to note that conditional on score fixed effects, the regressions give us the causal effect of losing relative to winning in round 1 on the willingness to compete in the subsequent rounds.

The regression results in columns 1 and 2 confirm that the gender difference in the reaction to losing for those who initially compete found in the main experiment 
Figure 8: Average number of times competition is chosen in rounds 2 to 4 by gender, initial choice and competition outcome in round 1 (feedback experiment)
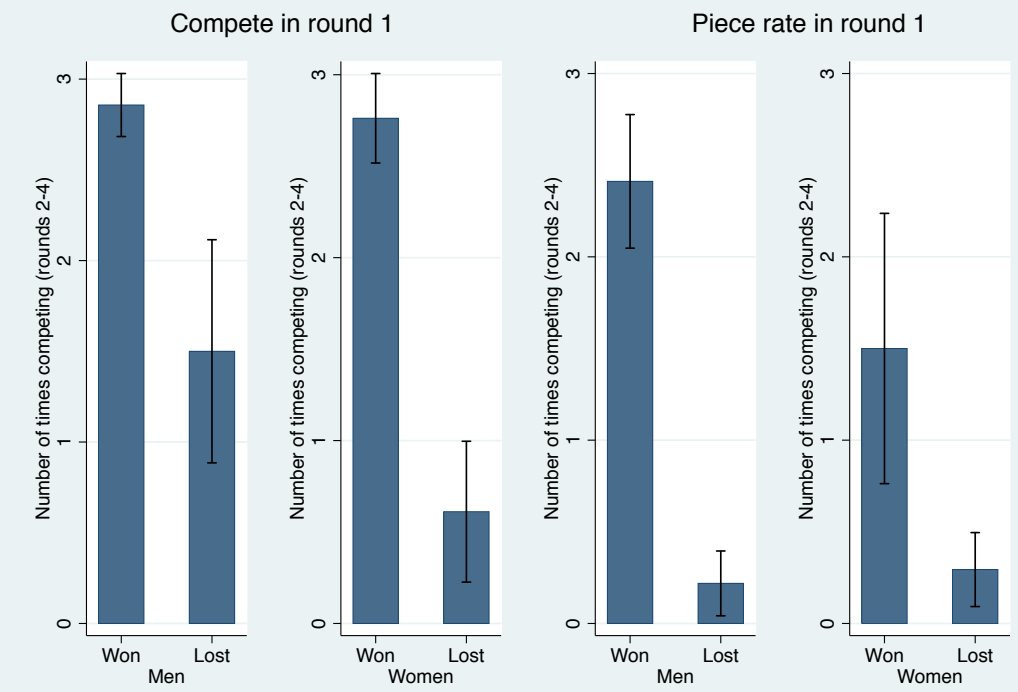

Note: The bars show the average number of times that participants chose to compete over rounds 2 to 4 . "Lost" denotes participants who lost in round 1 and "won" denotes participants who won in round 1 .

Table 5: Competition entry in rounds 2 to 4 (feedback experiment)

\begin{tabular}{|c|c|c|c|c|c|}
\hline & (1) & $(2)$ & & (3) & (4) \\
\hline & \multicolumn{2}{|c|}{ Competition in round 1 : } & & \multicolumn{2}{|c|}{ Piece rate in round 1 : } \\
\hline & All scores & $6 \leq$ Score $\leq 13$ & & All scores & $6 \leq$ Score $\leq 13$ \\
\hline \multirow[t]{2}{*}{ Female } & -0.024 & 0.075 & Female & 0.034 & 0.094 \\
\hline & $(0.072)$ & $(0.101)$ & & $(0.050)$ & $(0.067)$ \\
\hline \multirow[t]{2}{*}{ Round 1 loser } & $-0.291^{* *}$ & $-0.250^{*}$ & Round 1 winner & $0.565^{* * *}$ & $0.611^{* * *}$ \\
\hline & $(0.125)$ & $(0.133)$ & & $(0.090)$ & $(0.090)$ \\
\hline \multirow[t]{2}{*}{ Female $x$ loser } & $-0.274^{* *}$ & $-0.371^{* *}$ & Female $x$ winner & $-0.294^{* *}$ & $-0.382^{* * *}$ \\
\hline & $(0.129)$ & $(0.151)$ & & $(0.115)$ & $(0.129)$ \\
\hline Score fixed effects & $\sqrt{ }$ & $\sqrt{ }$ & & $\sqrt{ }$ & $\sqrt{ }$ \\
\hline Round 1 rank & $\sqrt{ }$ & $\sqrt{ }$ & & $\sqrt{ }$ & $\sqrt{ }$ \\
\hline Observations & 261 & 174 & & 291 & 213 \\
\hline Individuals & 87 & 58 & & 97 & 71 \\
\hline
\end{tabular}

Note: The table shows coefficients from OLS regressions of a gender dummy, a dummy for having lost (won) the round 1 competition and the interaction of the two on a binary indicator for choosing the competition in rounds 2 to 4 . Each choice is a separate observation and standard errors are clustered at the individual level. Score and round 1 rank mean score and normalised within-session rank in round 1. Clustered standard errors in parentheses. 
replicates. While male losers are 29 percentage points less likely to choose competition in round 2 to 4 compared to male winners, this effect is 57 percentage points for women. The regression results in columns 3 and 4 show that there is also a gender difference in the effect of positive feedback on future willingness to compete for those who are initially not willing to compete. Whereas men who win are 57 percentage points more likely to compete over the following three rounds than men who lose, this effect is only 27 percentage points for women.

\subsection{The role of gender differences in confidence, belief updating, and performance}

The results presented so far have shown that a gender gap in willingness to compete appears with experience even within the subgroups of individuals who initially choose to compete or not to compete. At the origin of these emerging gender gaps is a strong gender difference in the reaction to losing and winning. The experimental economics literature suggests several potential mechanisms behind these gender differences which my data allow me to explore, namely gender differences in initial confidence, belief updating, and the evolution of relative performance over time. Initial confidence is measured by the participants' predicted rank at the start of round 1, belief updating is measured by the change in predicted rank over time, and relative performance is measured by the change of actual rank over time. These mechanisms are explored in Table 6 using OLS regressions. Column 1 replicates the analyses in column 1 of Table 3 and columns 1 and 3 of Table 5. I then control for each potential mechanism. If a mechanism has explanatory power for the gender difference in the reaction to competition outcomes, the magnitude of the gender-interaction coefficient should shrink.

Most studies on gender differences in competitiveness find that, conditional on performance, women tend to be less confident than men (Niederle and Vesterlund, 2011), which is also the case in my sample. ${ }^{9}$ A loss could therefore more easily push women's confidence below the threshold at which they are no longer willing to compete. This is explored in column 2 by controlling for confidence at the start of round 1 and the interaction of confidence and the dummy for having lost(won) the first-round competi-

\footnotetext{
${ }^{9}$ Regressing initial confidence in the main experiment (predicted probability of winning in round 1 ) on gender and performance in round 1 , the coefficient on the female dummy is -0.081 (0.032) meaning that conditional on performance the average woman thinks that it is around 8 percentage points less likely that she will win a competition than the average man.
} 
tion. ${ }^{10}$ The gender difference in the reaction to losing for those who initially compete is hardly affected. For the main experiment, the coefficient actually increases in magnitude. However, the gender difference in the reaction to positive feedback shrinks by around 40 percent for those who initially choose the piece rate.

Likewise, if women update their beliefs more strongly in response to losing than men, this could explain why women's willingness to compete drops more strongly after a loss than men's willingness to compete. This is explored in the regressions in column 3 which control for confidence at the start of each round. ${ }^{11}$ For those who initially compete, the magnitude of the coefficient on the gender interaction actually increases slightly, meaning that men update their beliefs more in response to losing than women. ${ }^{12}$ For those who initially pick the piece rate, the gender-interaction coefficient drops by 37 percent.

Past studies have shown that women might perform worse after losing in a competition compared to men in the same situation (Buser, 2016; Gill and Prowse, 2014). In column 4, I control for normalised rank (that is, likelihood of winning) in each round. ${ }^{13}$ The interaction coefficient does not change much in any of the regressions and the gender difference in the effect of losing actually increases in both datasets.

Finally, I combine all four mechanisms in column 5. It becomes apparent that gender differences in confidence, belief updating, and performance changes can explain an important part of the gender difference in the response to positive feedback for those who do not compete in round 1, mainly due to the explanatory power of gender differences in initial beliefs and belief updating. On the other hand, these mechanisms cannot explain the gender difference in the reaction to losing for those who initially choose to compete. Conditional on initial beliefs, belief updating, and the evolution of relative performance, the magnitude of the gender-interaction coefficient actually

\footnotetext{
${ }^{10}$ The likelihood of entering competition is not necessarily linear in confidence. In particular, a risk neutral person would compete if they think their chance of winning is above 50 percent and would choose the piece rate otherwise. To make the regressions more flexible, I also include a dummy indicating that the predicted chance of winning is above 50 percent and include full interactions of this dummy with the continuous confidence variable and the competition outcome dummy.

${ }^{11}$ Again, to make the regressions more flexible I also include a dummy indicating that the predicted chance of winning is above 50 percent and include full interactions of this dummy with the continuous confidence variable and the competition outcome dummy.

${ }^{12}$ This fits with the results of Möbius et al. (2011) who find that men update beliefs about their own abilities more strongly than women following both positive and negative feedback.

${ }^{13}$ Again, to make the regressions more flexible, I also include a dummy indicating that the chance of winning is above 50 percent and include full interactions of this dummy with the continuous rank variable and the competition outcome dummy.
} 
Table 6: Competition entry after round 1: the role of confidence and performance in explaining the gender difference in the reaction to competition outcomes

\begin{tabular}{|c|c|c|c|c|c|}
\hline & $(1)$ & $(2)$ & $(3)$ & (4) & $(5)$ \\
\hline & \multicolumn{5}{|c|}{ Competition in round 1 (main experiment) } \\
\hline Female $x$ round 1 loser & $\begin{array}{c}-0.349^{* *} \\
(0.144)\end{array}$ & $\begin{array}{c}-0.386^{* * *} \\
(0.134)\end{array}$ & $\begin{array}{c}-0.354^{* * *} \\
(0.128)\end{array}$ & $\begin{array}{c}-0.373^{* *} \\
(0.142)\end{array}$ & $\begin{array}{c}-0.424^{* * *} \\
(0.129)\end{array}$ \\
\hline \multirow[t]{2}{*}{$\mathrm{N}$} & 460 & 460 & 460 & 460 & 460 \\
\hline & \multicolumn{5}{|c|}{ Competition in round 1 (feedback experiment) } \\
\hline Female $x$ round 1 loser & $\begin{array}{c}-0.274^{* *} \\
(0.129)\end{array}$ & $\begin{array}{l}-0.255^{*} \\
(0.143)\end{array}$ & $\begin{array}{c}-0.283^{* *} \\
(0.112)\end{array}$ & $\begin{array}{c}-0.299 * * \\
(0.126)\end{array}$ & $\begin{array}{c}-0.297^{* *} \\
(0.125)\end{array}$ \\
\hline \multirow[t]{2}{*}{$\mathrm{N}$} & 261 & 261 & 261 & 261 & 261 \\
\hline & \multicolumn{5}{|c|}{ Piece rate in round 1 (feedback experiment) } \\
\hline Female $x$ round 1 winner & $\begin{array}{c}-0.294^{* *} \\
(0.115)\end{array}$ & $\begin{array}{l}-0.177 \\
(0.119)\end{array}$ & $\begin{array}{c}-0.186^{*} \\
(0.110)\end{array}$ & $\begin{array}{c}-0.272^{* *} \\
(0.104)\end{array}$ & $\begin{array}{l}-0.131 \\
(0.099)\end{array}$ \\
\hline $\mathrm{N}$ & 291 & 291 & 291 & 291 & 291 \\
\hline $\mathrm{R} 1 \operatorname{conf} x$ Win R1 & & $\sqrt{ }$ & & & $\sqrt{ }$ \\
\hline Confidence & & & $\sqrt{ }$ & & $\sqrt{ }$ \\
\hline Rank & & & & $\sqrt{ }$ & $\sqrt{ }$ \\
\hline R1 score fixed effects & $\sqrt{ }$ & $\sqrt{ }$ & $\sqrt{ }$ & $\sqrt{ }$ & $\sqrt{ }$ \\
\hline R1 rank & $\sqrt{ }$ & $\sqrt{ }$ & $\sqrt{ }$ & $\sqrt{ }$ & $\sqrt{ }$ \\
\hline
\end{tabular}

Note: The table shows coefficients from OLS regressions of a gender dummy, a dummy for having won the round 1 competition and the interaction of the two on a binary indicator for choosing the competition in the subsequent rounds. R1 score means score in round $1, \mathrm{R} 1$ rank means normalised within-session rank in round $1, \mathrm{R} 1$ conf means probability of winning in round 1 as predicted by the participant, confidence means confidence at the start of each round and rank means rank in each round. Standard errors in parentheses. Standard errors are clustered at the individual level. 
increases in both datasets.

\section{Discussion and conclusions}

Differences in willingness to compete between men and women of equal talent are well documented in the experimental economics literature. Moreover, gender differences in willingness to compete in the lab have been shown to partially explain gender differences in career choices and labour market earnings. This study asks what happens to the gender gap in competitiveness over time as people accumulate experience. The experimental evidence I present shows that it is far from certain that the type of noisy feedback people typically accumulate over their careers serves to eliminate differences in willingness to compete between equally well-performing men and women.

Particularly striking is the fact that a significant gender difference appears over time even for those individuals who start out competing. At the root of my findings is a strong gender difference in the reaction to competition outcomes. Among the participants who compete at the beginning, men are much less likely to stop competing following a loss than women. Conversely, among the participants who do not compete at the start, men are more likely to persistently compete following positive feedback than are women.

If these findings translate from the stylised lab setting to career settings, they could be relevant for explaining gender differences in career choices and outcomes. In particular, the gender difference in the reaction to losing amongst those who are initially willing to compete is a plausible explanation for the so-called "leaking pipeline". For example, in European universities, women make up 59 percent of graduates, 46 percent of PhDs, 37 percent of associate professors and only 20 percent of full professors. In science and engineering women make up 35 percent of $\mathrm{PhD}$ graduates, 23 percent of associate professors, and just 11 percent of full professors (European Commission, 2013). Similarly, the higher up the corporate ladder one goes, the smaller the share of women (Bertrand and Hallock, 2001). Bertrand, Goldin, and Katz (2010), using a sample of MBA graduate from a top business school, show that although male and female graduates earn similar salaries right after graduation, men earn almost twice as much only a decade later.

In the competition for journal space, research funding and academic positions, persisting in the face of failure is arguably crucial for being successful in academia. Simi- 
larly, it is difficult to imagine somebody making it to the top of the corporate hierarchy without losing out to competitors at some point on the way. My results also show that the gender difference in the reaction to competition outcomes is at least as strong if not stronger for high performers who are initially willing to compete. These are exactly the people we would want (and expect) to become future full professors and executives. This suggests that bad luck early on in a career could be especially costly for high-performing women and introduces an important element of path dependence in the careers of women.

The documented gender differences in the reaction to positive feedback for those who initially do not compete can be at least partially explained by gender differences in initial confidence, belief updating, and performance changes for those who initially do not compete. The regressions in Section 3.2 show that these mechanisms can explain at least half of the gender difference for this group. The controls for confidence and performance are surely measured with error. Although I try to ameliorate this problem by using the controls in a flexible way (Gillen, Snowberg, and Yariv, 2015), this means that these mechanisms potentially explain an even larger share of the gender difference than suggested by the regression results.

On the other hand, changes in performance and confidence cannot explain the gender difference in the reaction to losing for those who are initially willing to compete, an especially interesting population to study if one is interested in the question why so many women drop out on the way to the top. Even though the mechanism controls are measured with error, it seems safe to conclude that they have no explanatory power for this population as the gender difference is actually larger conditional on the controls.

While gender differences in confidence, belief updating, and performance changes can therefore not explain why more women than men drop out of competition following a loss, the psychology literature on gender differences in the reaction to success and failure gives some hints for potential psychological mechanisms. According to this literature, men tend to attribute success to internal factors (such as talent) and failure to external factors (such as effort or lack thereof) while women tend to do the opposite (Dweck et al., 1978; Ryckman and Peckham, 1987).

A natural next step would be to examine whether the gender difference in the reaction to competition outcomes translates to career settings. Detailed long-term panel data on individual career decisions, outcomes, and performance would be ideal but is hard to come by. A potential alternative is offered by data from professional sports, with the caveats that mixed-gender competition is rare, samples are highly selective, 
and identification of gender differences is complicated by the fact that the competitive setting and incentives are rarely equal for male and female athletes even within the same sport. There is a small number of papers which look at gender differences in the reaction to competition outcomes in high-level sports. The most relevant is Wozniak (2012), who finds that the effect of prior tournament outcomes on the propensity of entering further tournaments is similar for male and female tennis players. ${ }^{14}$ Also looking at tennis players, De Paola, Gioia, and Scoppa (2013) find that female, but not male, players perform worse after losing the first set. Finally, Legge and Schmid (2013) find that skiers who narrowly miss a place on the podium underperform in the next race, this effect being somewhat stronger for female skiers. A further interesting direction for research would be to investigate whether the propensity to give up competing after a loss in a lab experiment predicts individual career choices and outcomes.

\footnotetext{
${ }^{14} \mathrm{He}$ does find a subtle gender difference, though, in how long the effect of prior experience lasts, with men being more affected than women by outcomes further in the past.
} 


\section{References}

Berge, Lars Ivar Oppedal, Kjetil Bjorvatn, Armando Jose Garcia Pires, and Bertil Tungodden. 2015. "Competitive in the lab, successful in the field?" Journal of Economic Behavior \& Organization 118:303-317.

Bertrand, Marianne. 2011. "New Perspectives on Gender." In Handbook of Labor Economics, vol. 4B, edited by Orley Ashenfelter and David Card. Elsevier, 1543 - 1590.

Bertrand, Marianne, Claudia Goldin, and Lawrence F. Katz. 2010. "Dynamics of the Gender Gap for Young Professionals in the Financial and Corporate Sectors." American Economic Journal: Applied Economics 2 (3):228-55.

Bertrand, Marianne and Kevin F. Hallock. 2001. "The Gender Gap in Top Corporate Jobs." Industrial and Labor Relations Review 55 (1):3-21.

Buser, Thomas. 2016. "The impact of losing in a competition on the willingness to seek further challenges." Management Science forthcoming.

Buser, Thomas, Muriel Niederle, and Hessel Oosterbeek. 2014. "Gender, competitiveness and career choices." Quarterly Journal of Economics 129 (3):1409-1447.

Buser, Thomas, Erik Plug, and Lydia Geijtenbeek. 2015. "Do Gays Shy Away from Competition? Do Lesbians Compete Too Much?" Working paper. University of Amsterdam. .

Croson, Rachel and Uri Gneezy. 2009. "Gender differences in preferences." Journal of Economic Literature 47 (2):448-74.

De Paola, Maria, Francesca Gioia, and Vincenzo Scoppa. 2013. "Are Females scared of competing with males? Results from a field experiment." Working paper .

Dohmen, Thomas, Armin Falk, David Huffman, Uwe Sunde, Jurgen Schupp, and Gert G. Wagner. 2011. "Individual risk attitudes: Measurement, determinants, and behavioral consequences." Journal of the European Economic Association 9 (3):522550.

Dweck, Carol S, William Davidson, Sharon Nelson, and Bradley Enna. 1978. "Sex differences in learned helplessness: II. The contingencies of evaluative feedback in the 
classroom and III. An experimental analysis." Developmental psychology 14 (3):268276.

European Commission. 2013. "She Figures 2012. Gender in Research and innovation."

Fischbacher, Urs. 2007. "z-Tree: Zurich Toolbox for Ready-Made Economic Experiments." Experimental Economics 10 (2):171-178.

Flory, Jeffrey A., Andreas Leibbrandt, and John A. List. 2015. "Do competitive workplaces deter female workers? A large-scale natural field experiment on job-entry decisions." Review of Economic Studies 82 (1):122-155.

Gill, David and Victoria Prowse. 2014. "Gender Differences and Dynamics in Competition: The Role of Luck." Quantitative Economics 5 (2):351-376.

Gillen, Ben, Erik Snowberg, and Leeat Yariv. 2015. "Experimenting with Measurement Error: Techniques with Applications to the Caltech Cohort Study." NBER Working Paper No. 21517 .

Gneezy, Uri, Muriel Niederle, and Aldo Rustichini. 2003. "Performance In Competitive Environments: Gender Differences." The Quarterly Journal of Economics 118 (3):1049-1074.

Legge, Stefan and Lukas Schmid. 2013. "Rankings, Random Successes, and Individual Performance." Working paper .

Möbius, Markus, Muriel Niederle, Paul Niehaus, and Tanya Rosenblat. 2011. "Managing Self-Confidence: Theory and Experimental Evidence." Working paper .

Niederle, Muriel and Lise Vesterlund. 2007. "Do women shy away from competition? Do men compete too much?" The Quarterly Journal of Economics 122 (3):1067-1101.

- 2011. "Gender and competition." Annual Review of Economics 3 (1):601-630.

Reuben, Ernesto, Paola Sapienza, and Luigi Zingales. 2015. "Taste for competition and the gender gap among young business professionals." Working paper. Columbia University. .

Reuben, Ernesto, Matthew Wiswall, and Basit Zafar. 2015. "Preferences and Biases in Educational Choices and Labor Market Expectations: Shrinking the Black Box of Gender." Economic Journal forthcoming. 
Ryckman, David B and Percy D Peckham. 1987. "Gender differences in attributions for success and failure." The Journal of Early Adolescence 7 (1):47-63.

Wozniak, David. 2012. "Gender differences in a market with relative performance feedback: Professional tennis players." Journal of Economic Behavior $\&$ Organization 83 (1):158-171.

Wozniak, David, William T. Harbaugh, and Ulrich Mayr. 2014. "The Menstrual Cycle and Performance Feedback Alter Gender Differences in Competitive Choices." Journal of Labor Economics 32 (1):161-198.

Zhang, Y. Jane. 2012. "Can experimental economics explain competitive behavior outside the lab?" Working paper. 


\section{Appendix: Experimental screenshots}

\section{Main experiment}
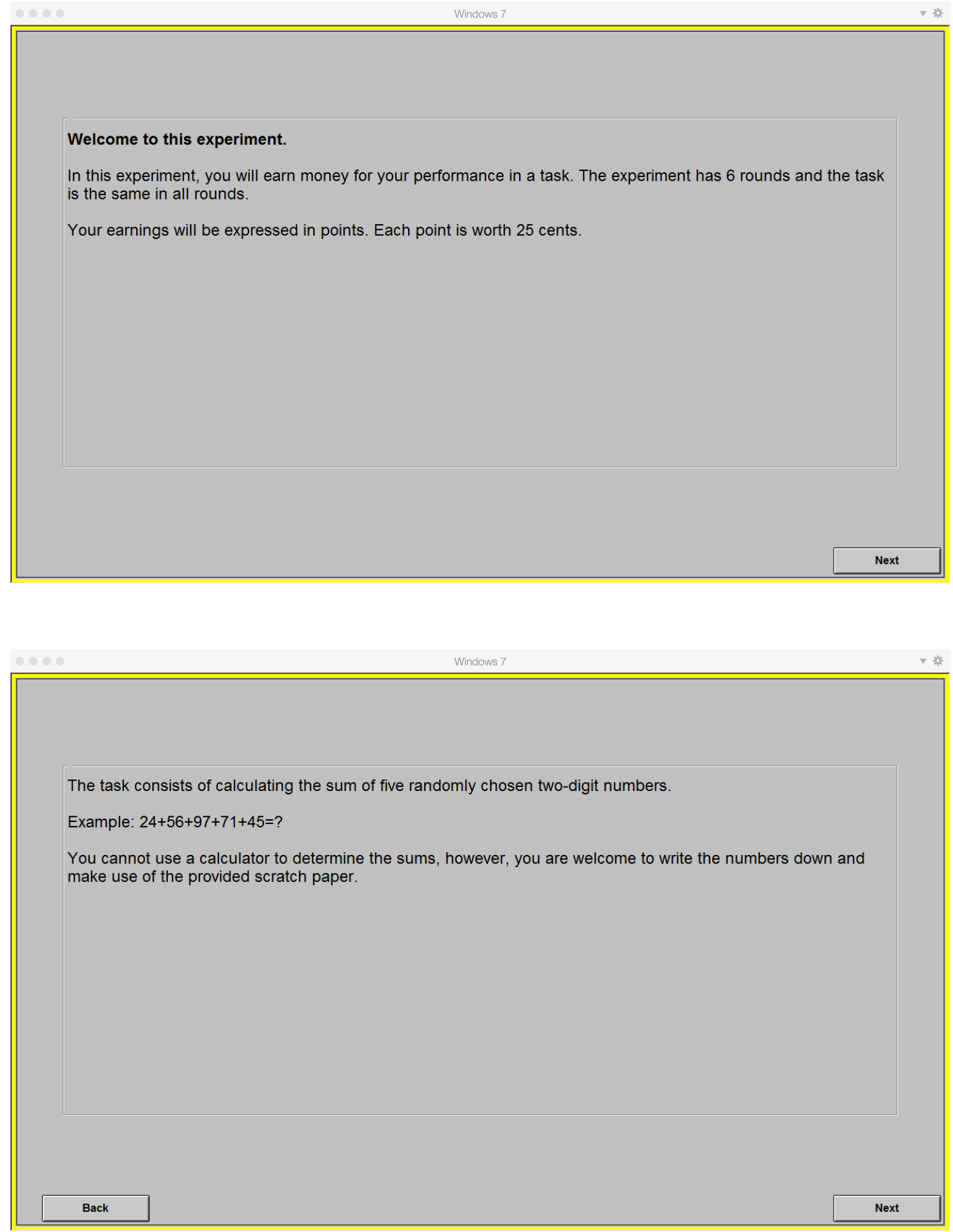

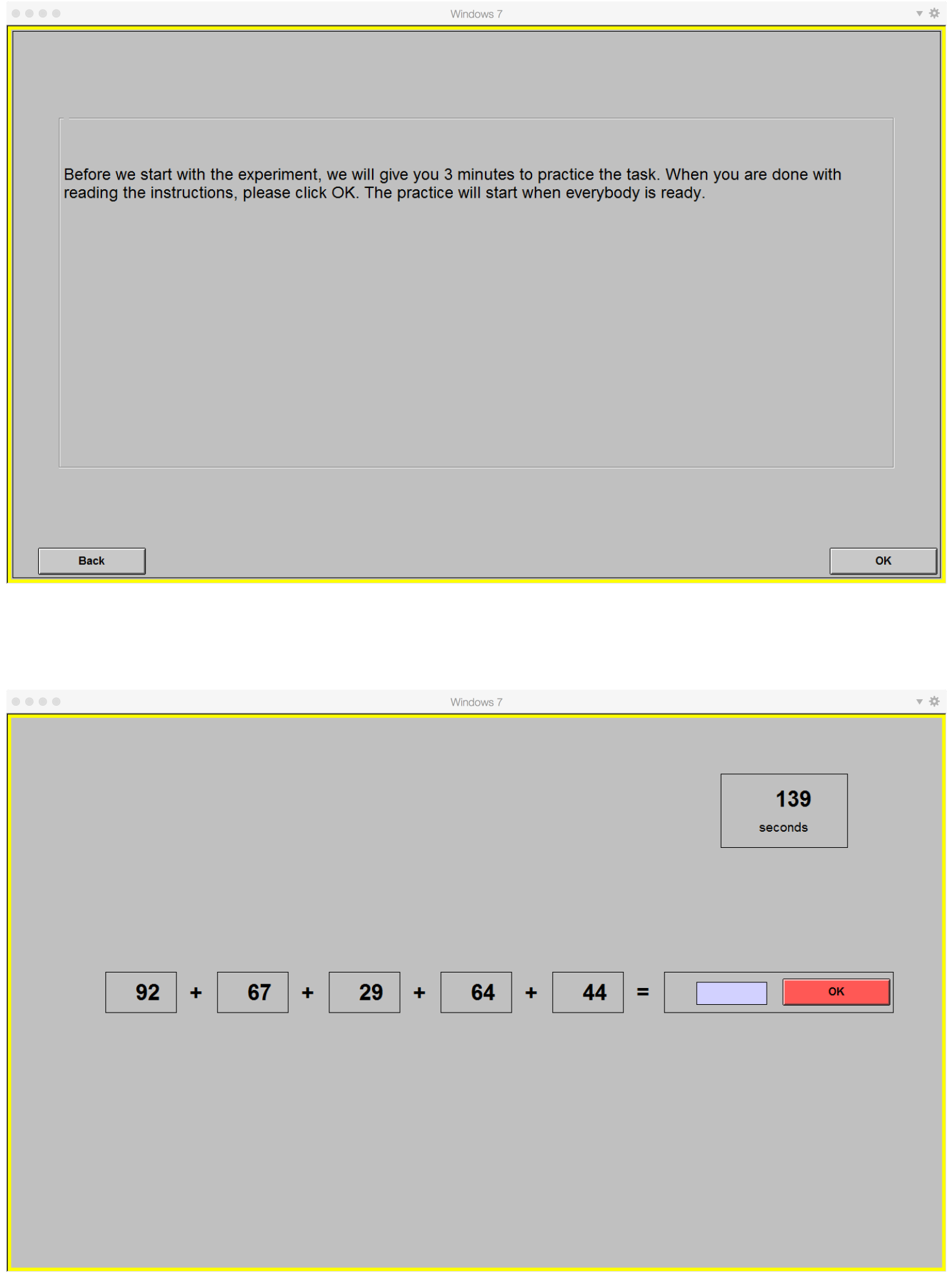

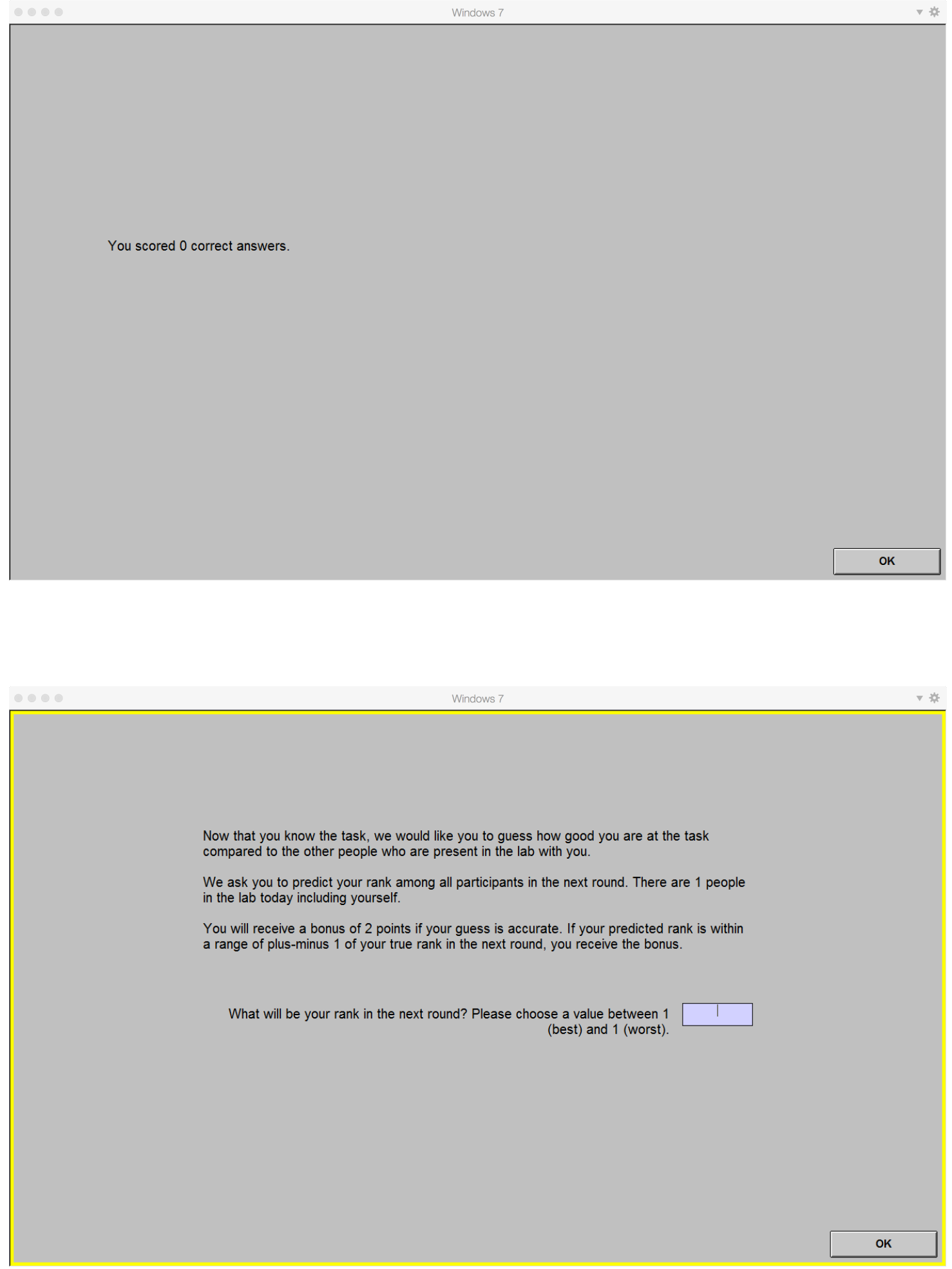

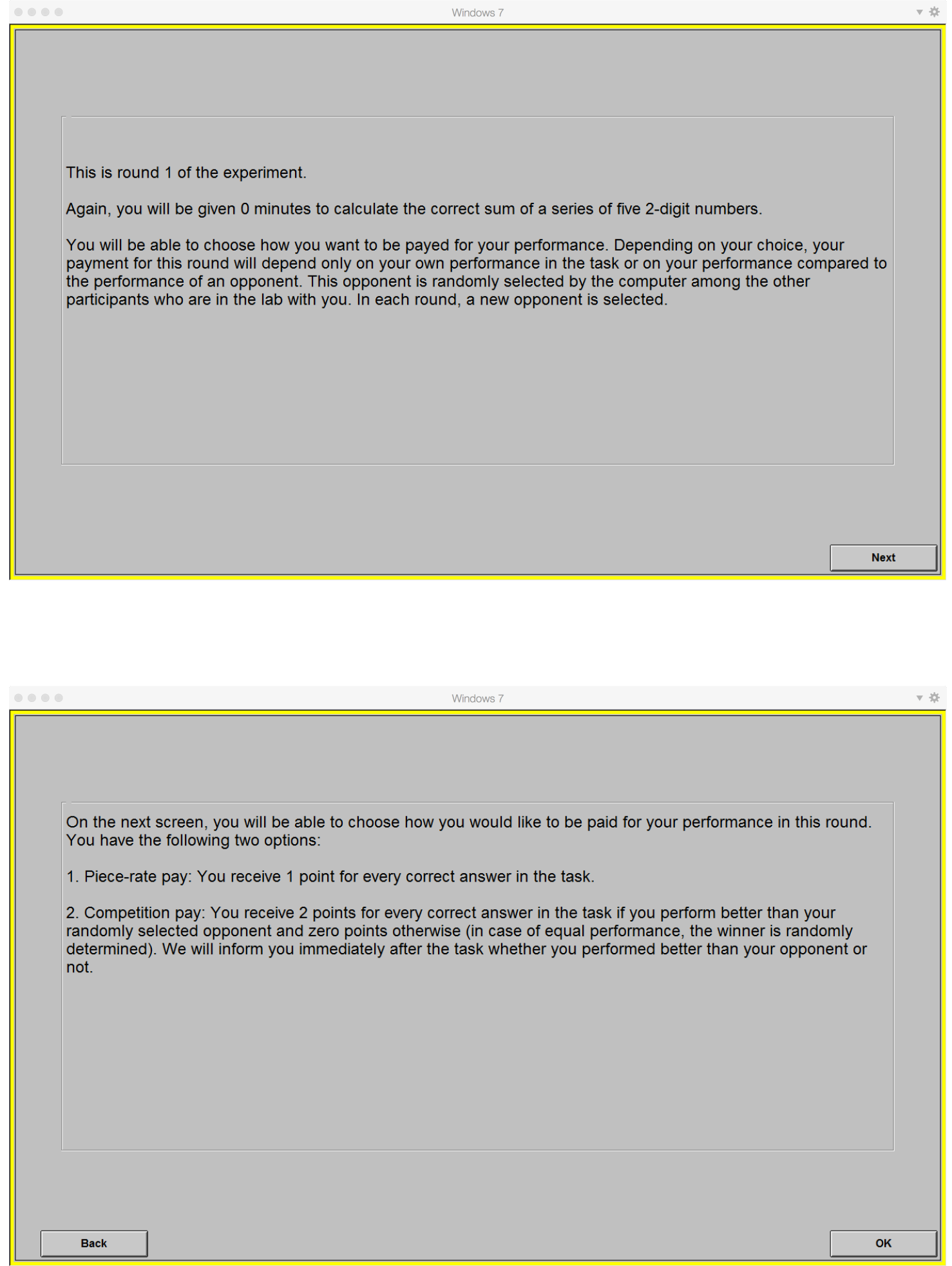

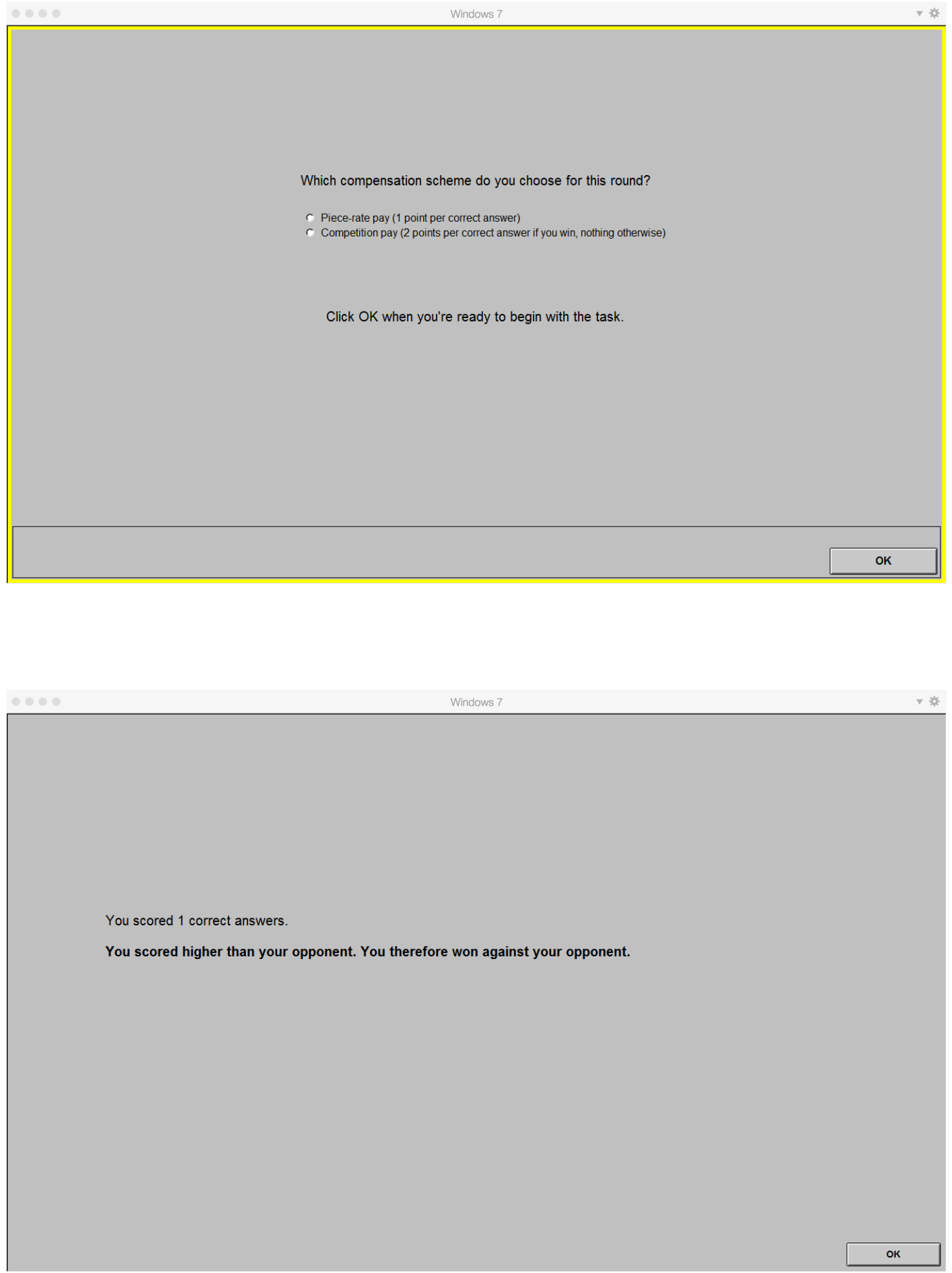

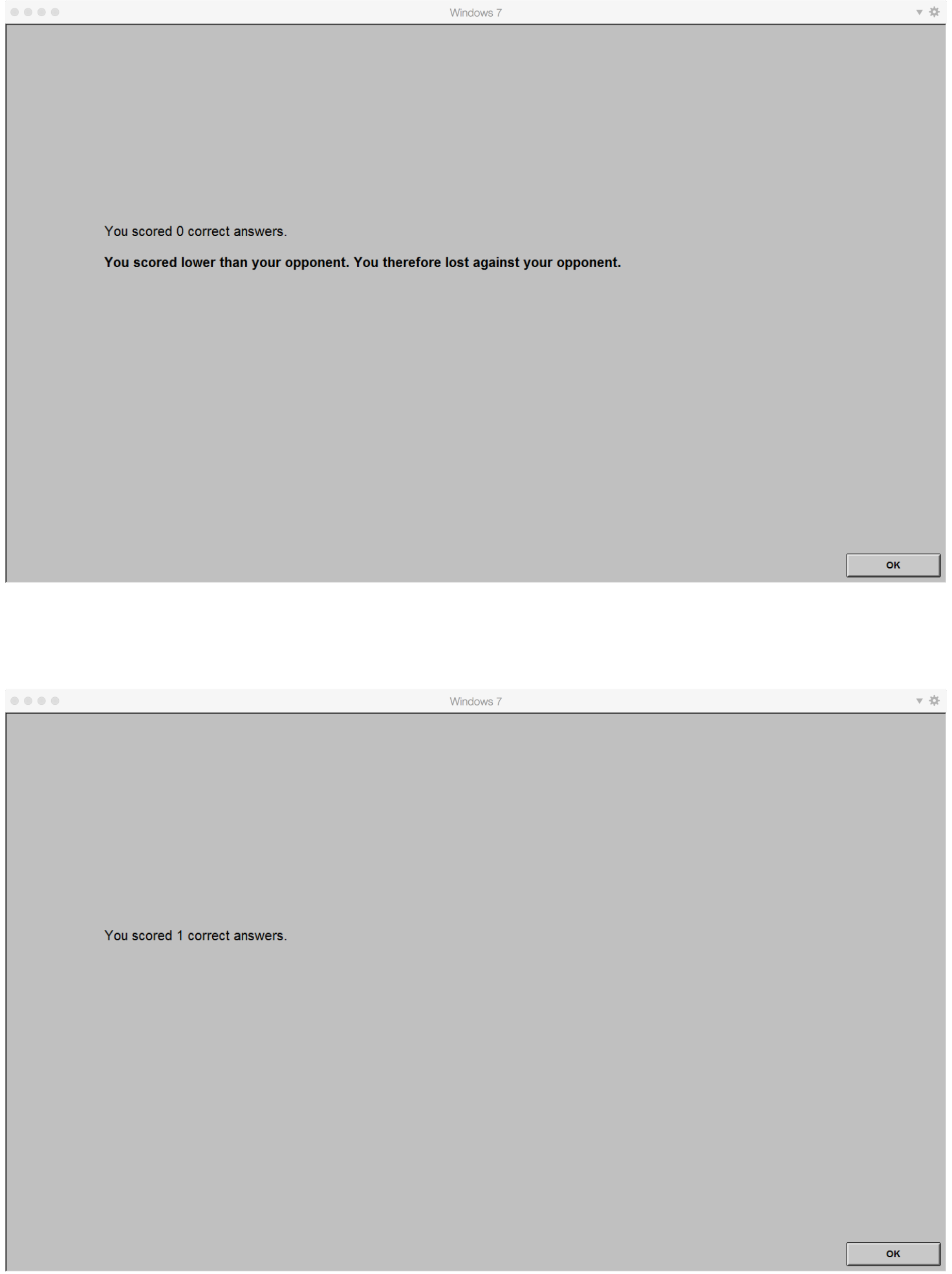

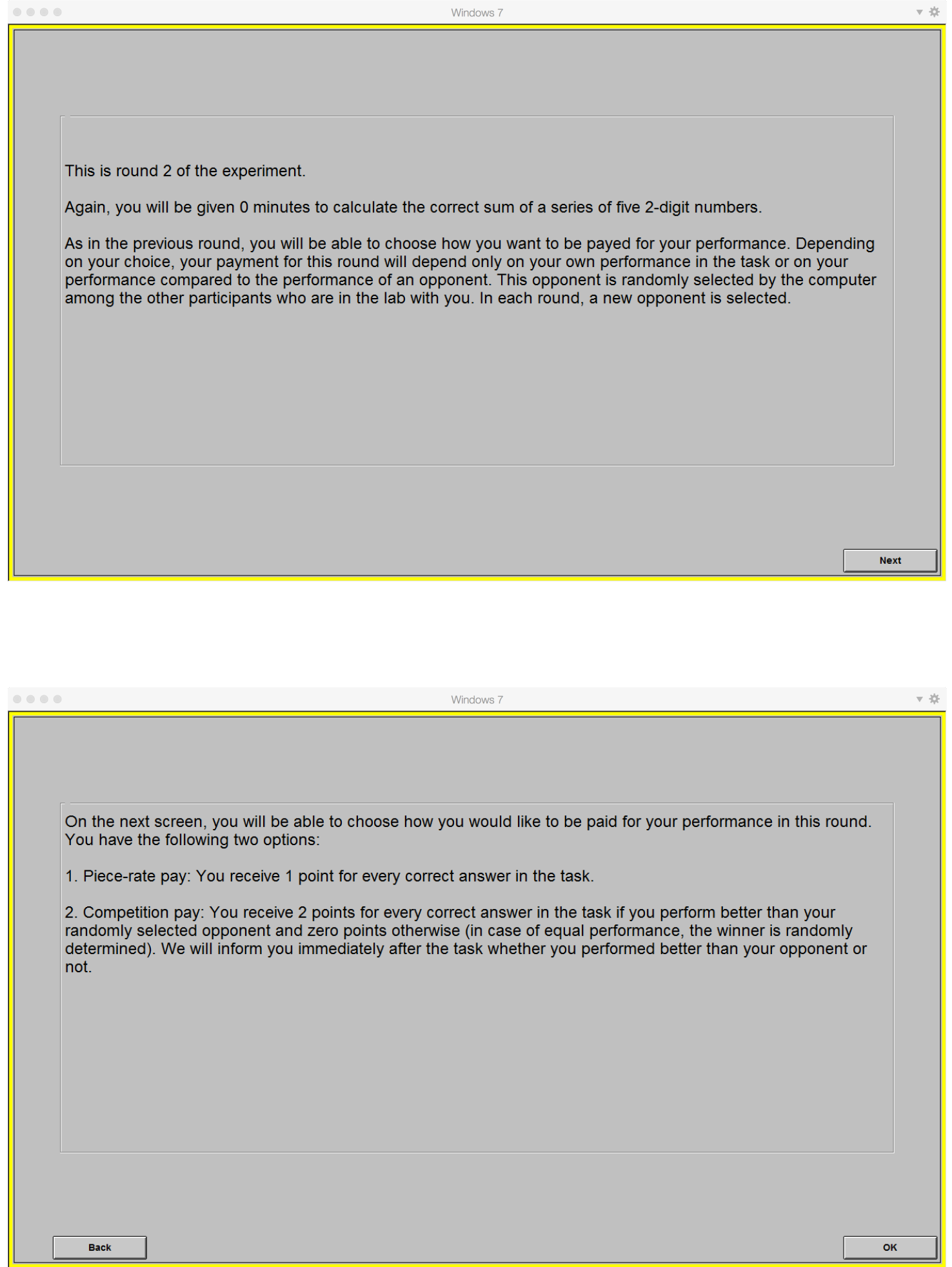

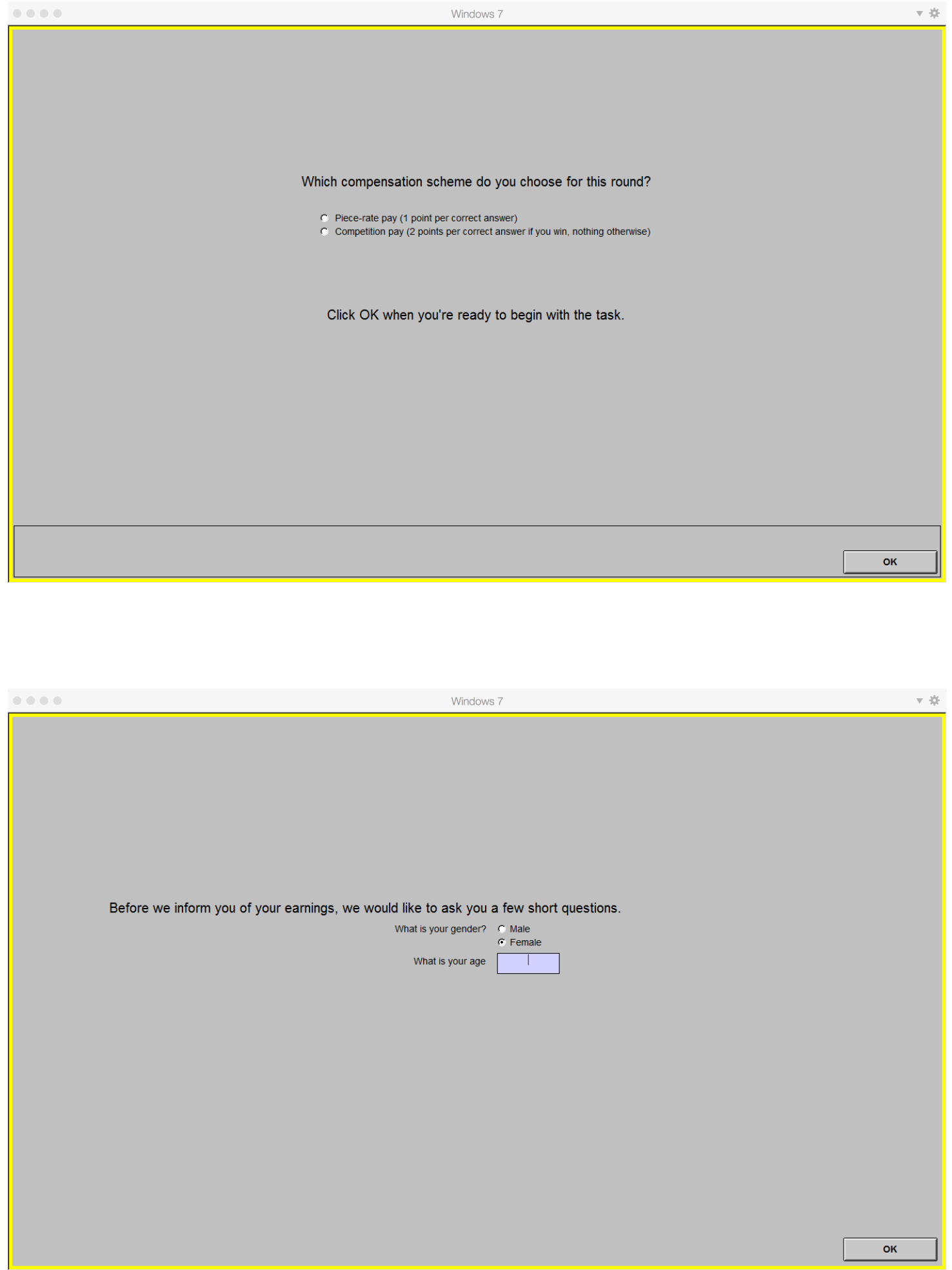


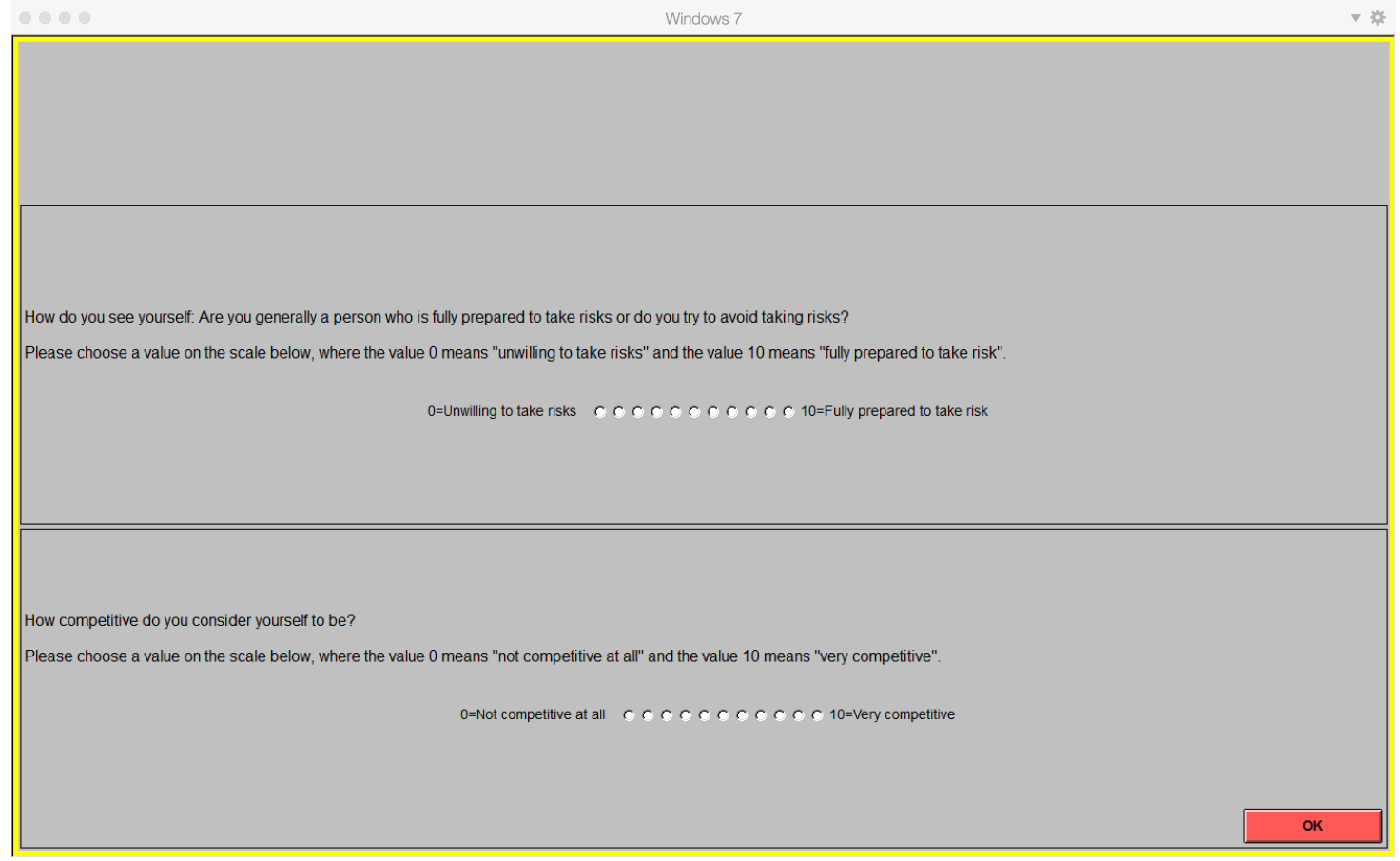




\section{Feedback experiment}
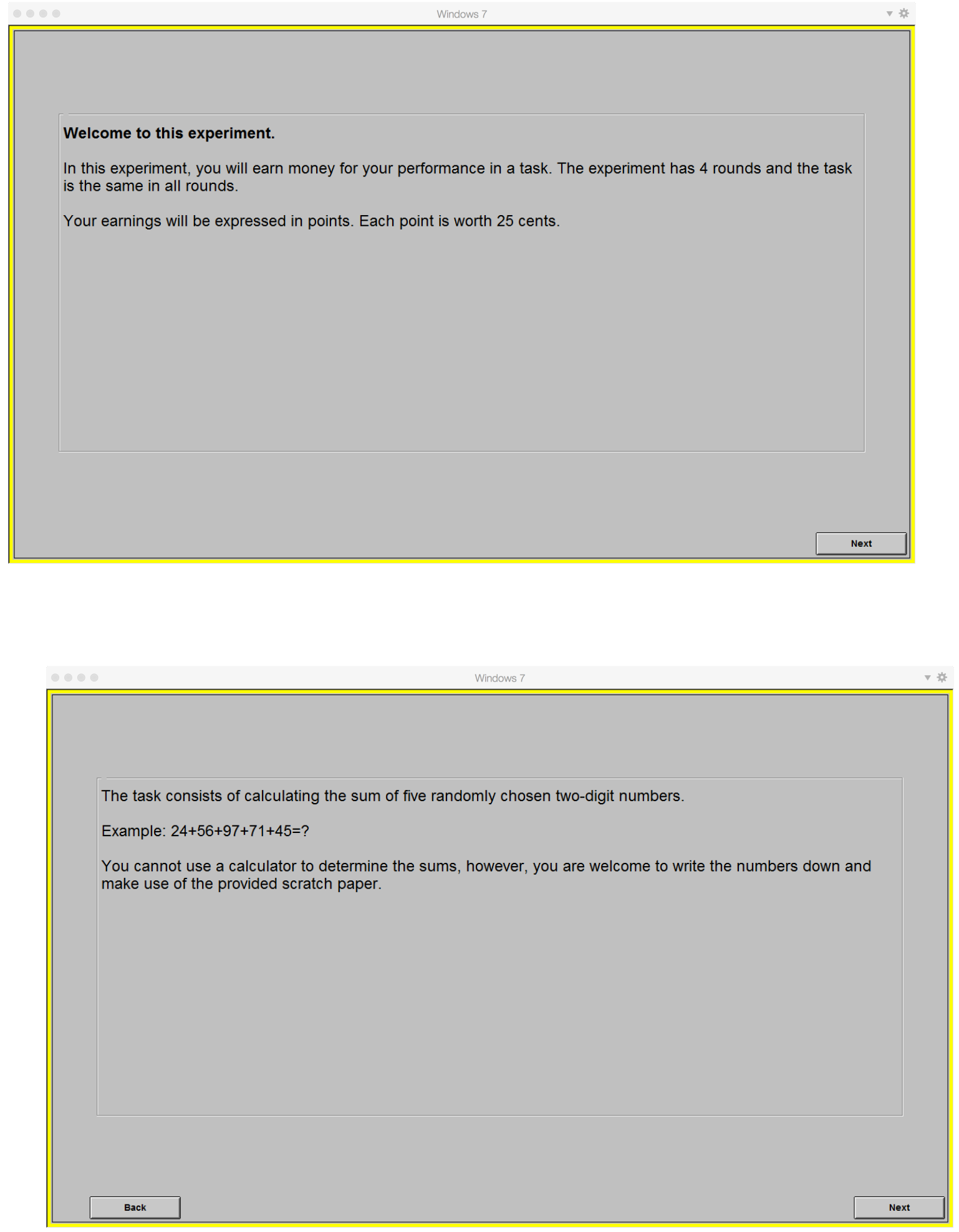

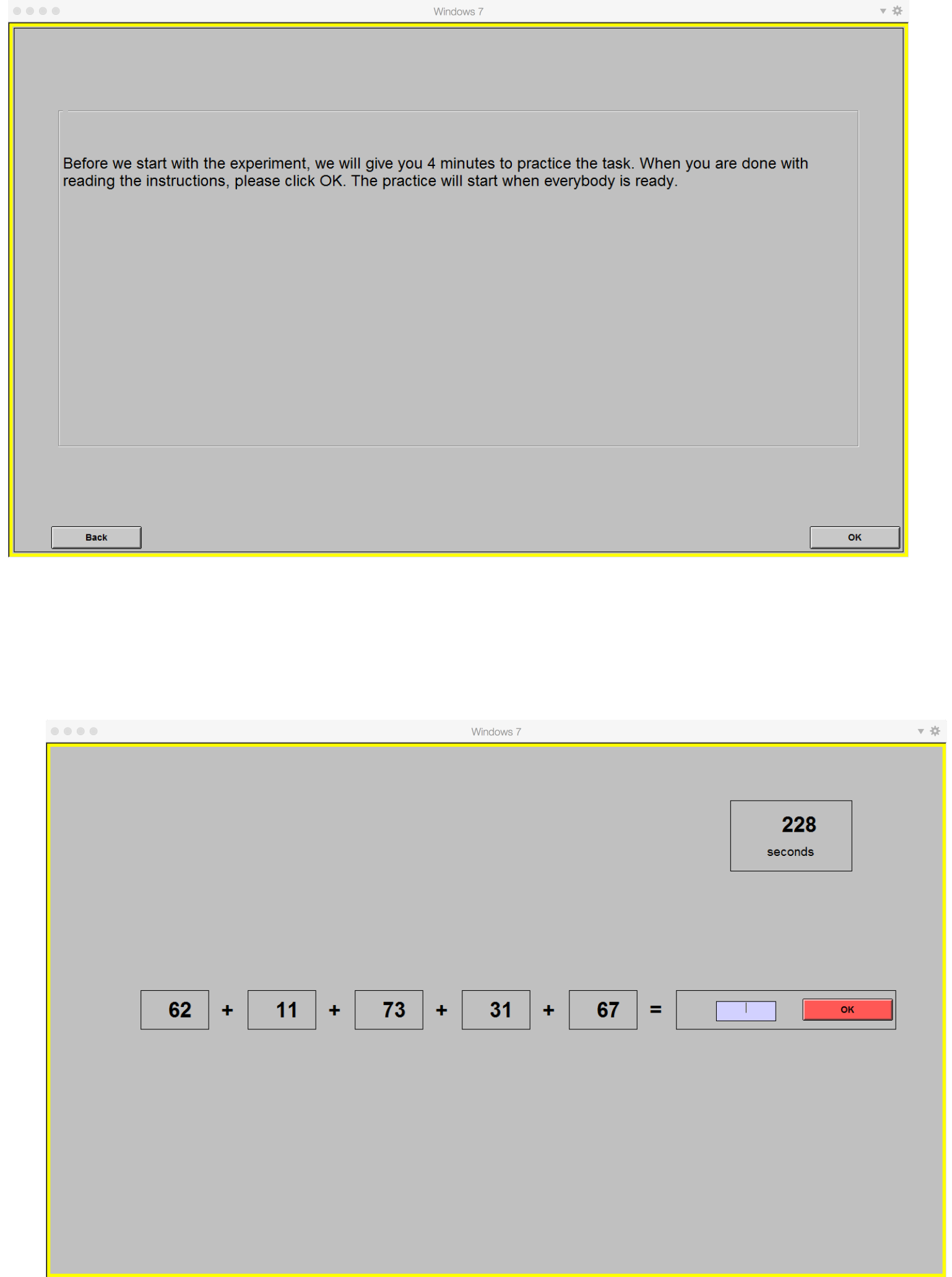

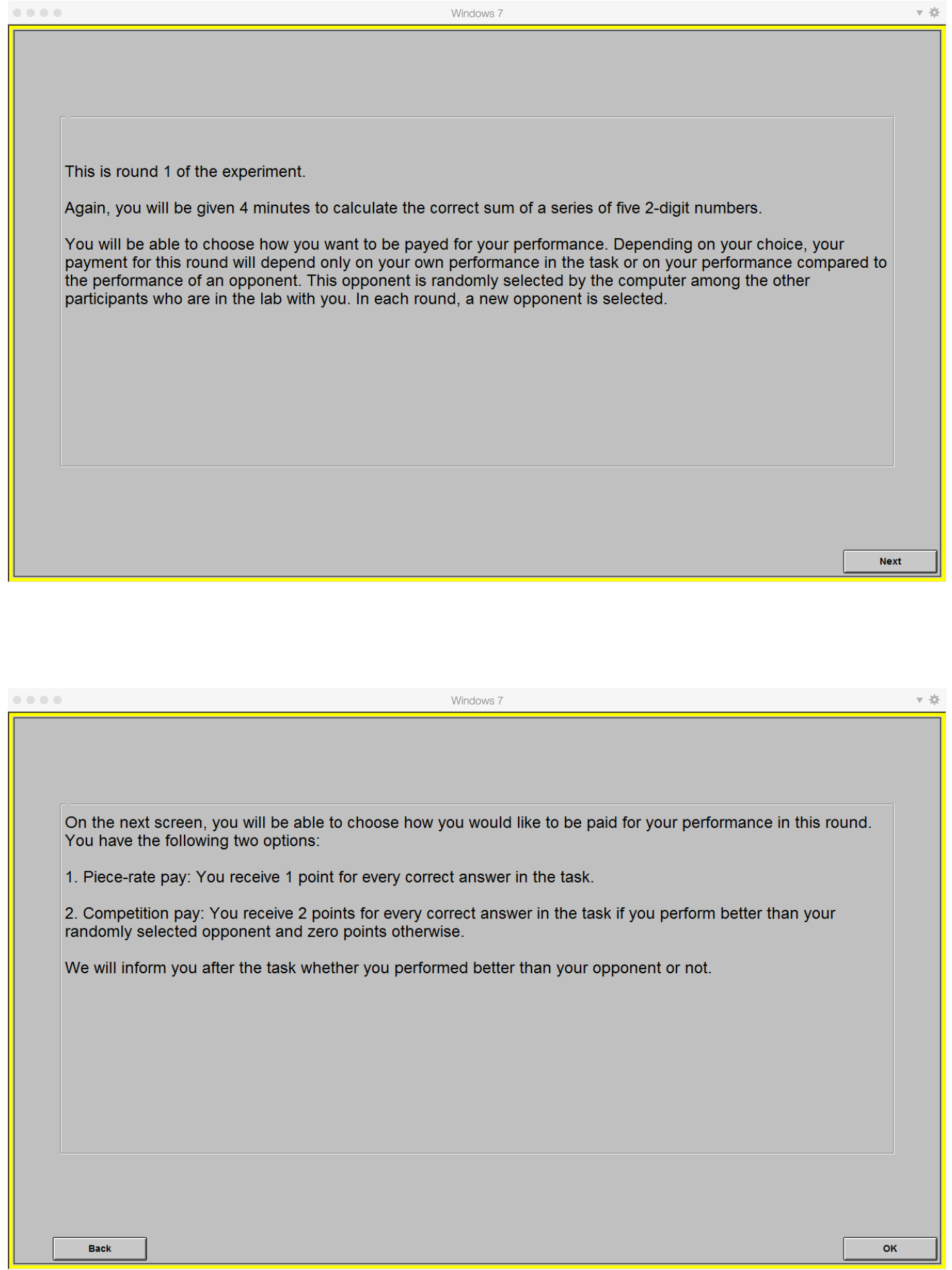

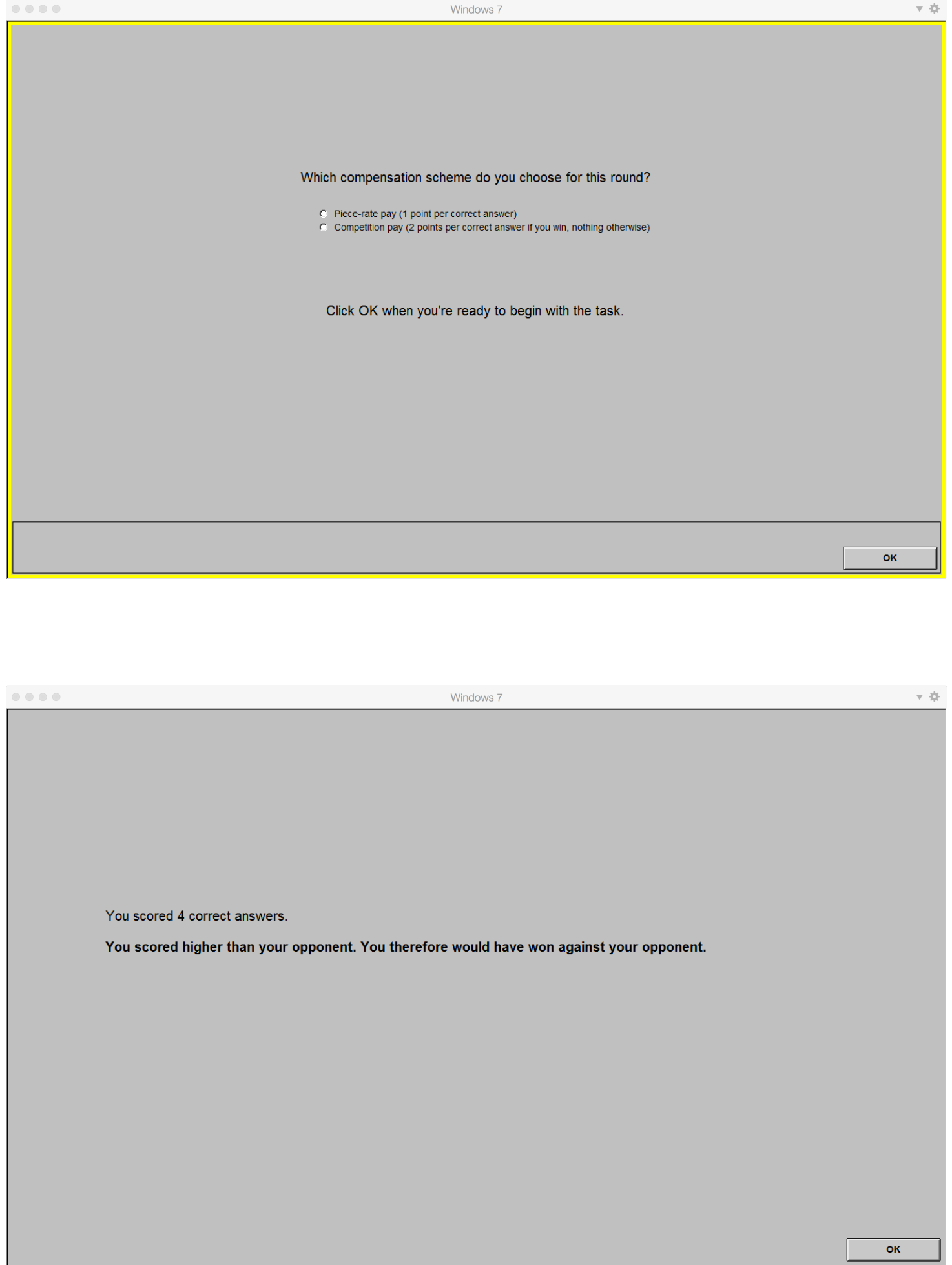


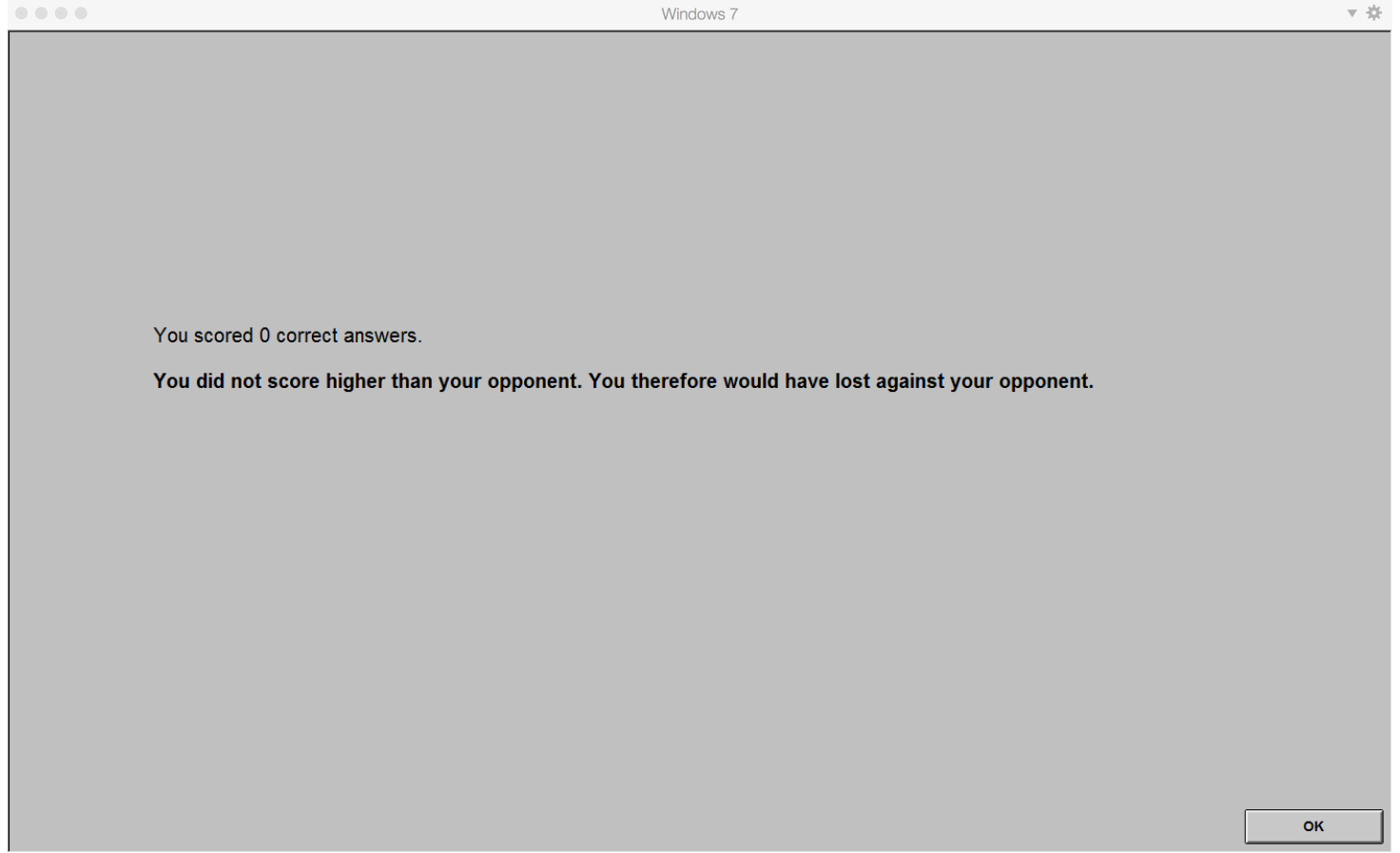

